\title{
Silencing LncRNA AK139328 protects vascular endothelial cells from ischemia-reperfusion injury by increasing PI3K/Akt signaling
}

\author{
Zeng-Yang Pei ${ }^{1}$, Sheng-Hao Wang ${ }^{1}$, Yan $\mathrm{Mao}^{2}$, $\mathrm{Qi} \mathrm{Li}^{1}$, Zi-Heng Wu${ }^{3}$ and Xiang-Tao \\ Zheng ${ }^{3}$ \\ ${ }^{1}$ Department of Veterinary Medicine, College of Animal Sciences, Zhejiang University, Hangzhou 310058, P.R. China \\ ${ }^{2}$ Pet Shield Animal Hospital, Xihu District, Hangzhou 310000, P.R. China \\ ${ }^{3}$ Department of Vascular Surgery, The First Affiliated Hospital of Medical School of Zhejiang University, Hangzhou 310003, \\ P.R. China \\ Correspondence to: Zeng-Yang Pei, email: peizengyang@zju.edu.cn \\ Keywords: LncRNA AK139328; vascular endothelial cells; ischemia-reperfusion; PI3K/Akt signaling pathway; rat model \\ Received: July 12,2016 Accepted: October 17, $2017 \quad$ Published: January 02, 2018
}

Copyright: Pei et al. This is an open-access article distributed under the terms of the Creative Commons Attribution License 3.0 (CC BY 3.0), which permits unrestricted use, distribution, and reproduction in any medium, provided the original author and source are credited.

\section{ABSTRACT}

We investigated the effects of IncRNA AK139328 and PI3K/Akt signaling during rat hindlimb ischemia-reperfusion (I/R) injury. Rat vascular endothelial cells (VECs) subjected to oxygen-glucose deprivation showed high IncRNA AK139328 expression and decreased PI3K/Akt signaling, whereas IncRNA AK139328 knockdown increased PI3K/Akt signaling in VECs. Correspondingly, gastrocnemius muscles from rats subjected to hindlimb I/R showed high levels of IncRNA AK139328 and low PI3K/Akt/eNOS signaling. I/R also increased serum levels of TNF-a, VCAM-1 and malondialdehyde, serum creatine kinase activity and the number of circulating endothelial cells (CECs). Gastrocnemius tissue from rats subjected to $I / R$ exhibited inflammation, apoptosis and trauma with loosely attached, swollen VECs associated with inflammatory immune cells. LncRNA AK139328 knockdown increased PI3K/ Akt/eNOS signaling in gastrocnemius muscles subjected to $I / R$, and decreased serum levels of TNF-a, VCAM-1 and malondialdehyde, serum creatine kinase activity and numbers of CECs. LnCRNA AK139328 knockdown also decreased inflammation, apoptosis and trauma in gastrocnemius muscles, which showed tightly attached VECs that were not associated with inflammatory immune cells. Inhibition of PI3K/ Akt signaling by wortmannin or LY294002 reversed the effects of IncRNA AK139328 knockdown. In conclusion, I/R induces expression of IncRNA AK139328, which suppresses PI3K/Akt signaling required to prevent I/R-related pathology in VECs.

\section{INTRODUCTION}

Ischemia-reperfusion $(\mathrm{I} / \mathrm{R})$ results in remote organ injury during treatment of patients with acute limb ischemia $[1,2]$. The extent of $\mathrm{I} / \mathrm{R}$ injury in myocardial infarction and peripheral vascular disease is determined by the magnitude of interruption in blood supply [3]. Remote organ dysfunction develops after reperfusion and is regulated by local humoral and/or cellular factors [4]. I/R injury, which is induced by clamping the femoral artery shows slow recovery despite rapid restoration of blood flow as well as successful surgery $[5,6]$. Reperfusion results in oxidative stress that elicits inflammatory response and induces kidney cell death [7].
Vascular endothelial cells (VECs) secrete various factors that modulate vascular permeability barrier and inflammation [8]. They produce periostin and inflammatory chemokines associated with allergic reactions [9]. Autophagy protects VECs during I/R injury [10]. Non-coding RNAs (ncRNAs) regulate growth and proliferation of human umbilical vein endothelial cells [11]. LncRNAs regulate embryonic stem cell maintenance and lineage-specific differentiation [12]. They play critical roles in mammalian neuronal development and activity [13]. LncRNAs influence diverse cellular functions like cell cycle, apoptosis, differentiation and morphogenesis [14]. LncRNA CGS21680 decreases hepatocyte death by activating the PKB/Akt signaling pathway [15]. PI3K/Akt signaling pathway 
regulates tumor necrosis factor-alpha (TNF- $\alpha)$ expression [16]. Silencing lncRNA AK139328 ameliorated liver I/R injury by activating Akt signaling [17]. In the mouse liver I/R injury model, we observed multiple dysregulated lncRNAs including lncRNA AK139328 in the plasma with potential as novel diagnostic and prognostic biomarkers for ischemic liver injury [18]. In this study, we investigated the role of lncRNA AK139328 and PI3K/Akt signaling in rat hindlimb I/R injury model.

\section{RESULTS}

\section{Identification and characterization of rat IncRNA AK139328}

We searched the rat genome database with BLAST using the mouse lncRNA AK139328 as the query sequence and found the evolutionarily conserved rat lncRNAAK139328 (Figure 1). Analysis of RNA-seq data in the SRA and ArrayExpress databases with TopHat and Cufflinks softwares localized the lncRNA AK139328 to rat chromosome 3 on the rat genome (Version: RGSC Rnor_6.0/rn6) of UCSC genome database (http://genome. ucsc.edu/) (Figure 2). We performed 3'- and 5' RACE to obtain the full length lncRNA AK139328 transcript (Figures 3 and 4). In vitro transcription \& translation assay showed that lncRNA AK139328 sequence was noncoding (Figure 5). RNA FISH analysis demonstrated high lncRNA AK139328 expression in the nucleus of rat VECs and slight expression in the cytoplasm (Figure 6).

\section{LncRNA AK139328 is highly expressed in oxygen-glucose deprived rat VECs}

We investigated the status of lncRNA AK139328 in rat VEC's induced by oxygen-glucose deprivation to mimic I/R. We observed that oxygen-glucose deprivation increased lncRNA AK139328 levels in rat VECs $(P<0.05$; Figure 7). Moreover, VECs transfected with si-AK139328 showed low lncRNA AK139328 levels than control VECs after oxygen-glucose deprivation $(P<0.05$; Figure 7).
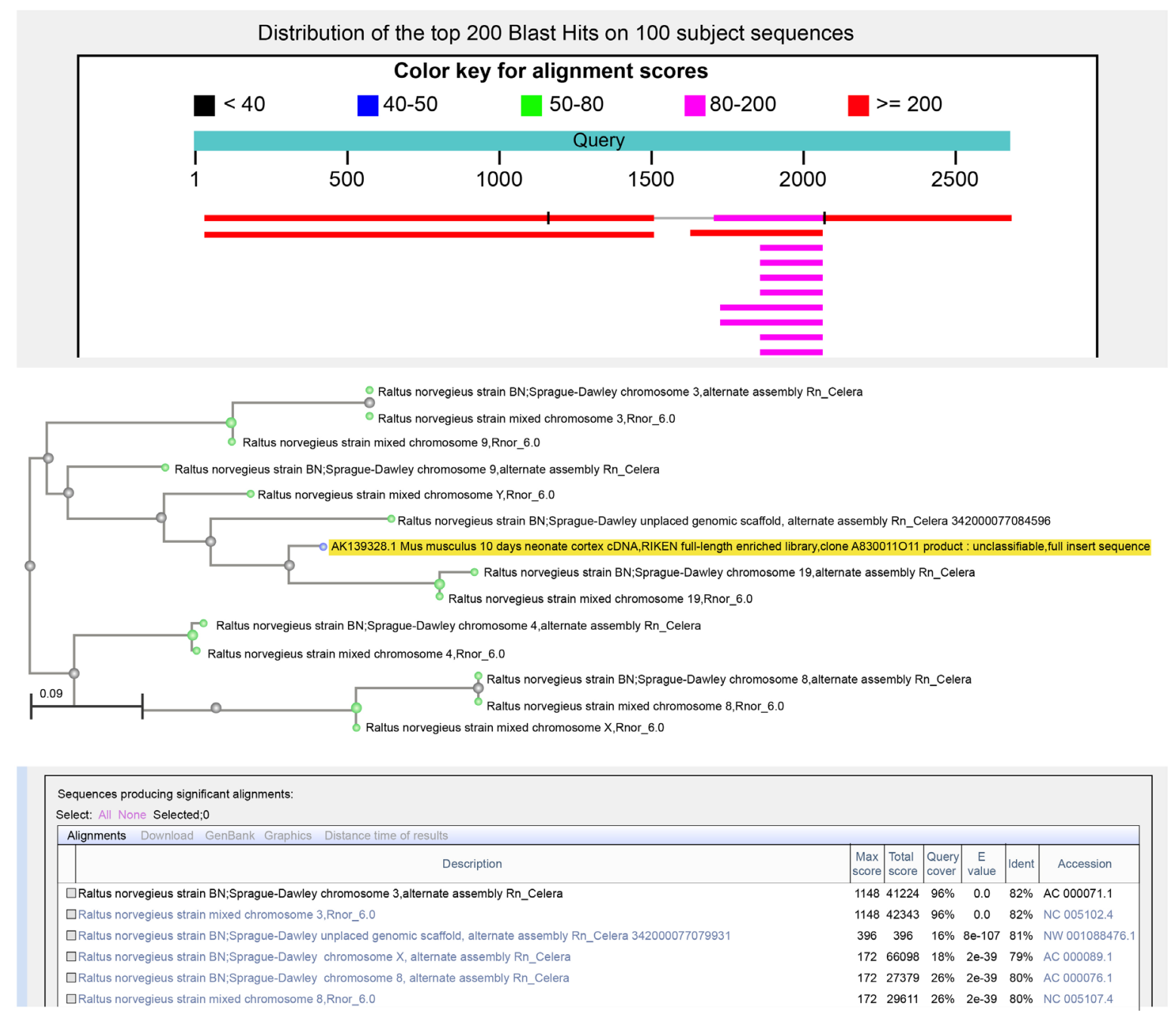

Figure 1: Sequence homology between mouse and rat IncRNA AK139328. Sequence alignment showing homology between the nucleotide sequences of mouse and rat lncRNA AK139328. 


\section{Status of PI3K/Akt signaling pathway in VEC model of $I / R$ injury}

Next, we analyzed the status of PI3K/Akt signaling pathway and ROS levels in the VEC cells upon oxygenglucose deprivation. PI3K/Akt signaling (total and phosphorylated PI3K and AKT) and ROS levels decreased when rat VECs were oxygen-glucose deprived (Figure 8 and Table 1). Moreover, rat VECs transfected with siAK139328 showed higher PI3K/Akt signaling and ROS levels than controls $(P<0.05$; Figure 8 , Table 1$)$. But, PI3K/AKT inhibitor LY294002 reversed the effects of lncRNA AK139328 silencing. The changes in PI3K and Akt mRNA and protein levels are shown in Figure 8A-8D.

\section{Status of IncRNA AK139328 expression in rat hindlimb I/R model}

Next, we analyzed the in vivo role of lncRNAAK139328 using the rat hindlimb I/R model. We observed increased lncRNA AK139328 expression in the gastrocnemius muscle of rats subjected to $\mathrm{I} / \mathrm{R}(P<0.05$; Figure 9). However, lncRNA AK139328 knockdown reduced its levels by $60 \%$ in the gastrocnemius muscle of rats subjected to $\mathrm{I} / \mathrm{R}(P<0.05$; Figure 9$)$.

\section{Status of PI3K/Akt signaling pathway, eNOS, ROS and caspase- 3 in rat hindlimb $I / R$ model}

Next, we analyzed levels of ROS as well as total and phosphorylated PI3K, Akt, eNOS protein levels in the rat hindlimb I/R model. Gastrocnemius muscle from rats subjected to $\mathrm{I} / \mathrm{R}$ showed reduced total and phosphorylated PI3K, Akt, eNOS as well as ROS levels $(P<0.05$; Figure 10; Table 2). However, rats subjected to I/R in presence of si-AK139328 demonstrated higher total and phosphorylated PI3K, Akt, eNOS as well as ROS levels than controls $(P<0.05$; Figure 10 ; Table 2$)$. The effect of lncRNA AK139328 knockdown was reversed by wortmannin, a PI3K/Akt inhibitor. This demonstrated that I/R induced lncRNA AK139328 that subsequently downregulated PI3K signaling pathway, eNOS and ROS. Moreover, IHC analysis demonstrated that $\mathrm{I} / \mathrm{R}$ induced caspase-3 expression in rat gastrocnemius muscles, but were decreased by lncRNA AK139328 silencing $(P<0.05$; Figure 11). Wortmannin treatment reversed the effects of IncRNA AK139328 silencing and increased caspase-3 expression (Figure 11).

\section{Effect of IncRNA AK139328 on morphological and ultrastructural changes in skeletal muscle in rat hindlimb I/R model}

H\&E stained skeletal muscle sections showed swollen, uneven and irregularly arranged muscle fibers upon I/R injury (Figure 12). Muscle cells showed severe swelling, fracture, enlargement, lighter color, narrow intercellular space and loosely arranged vascular wall layers. The VECs were also swollen and loosely attached to the internal elastic membrane with the nucleus protruding to the lumen. In some cases, VECs were either found in the lumen or disappeared. Inflammatory

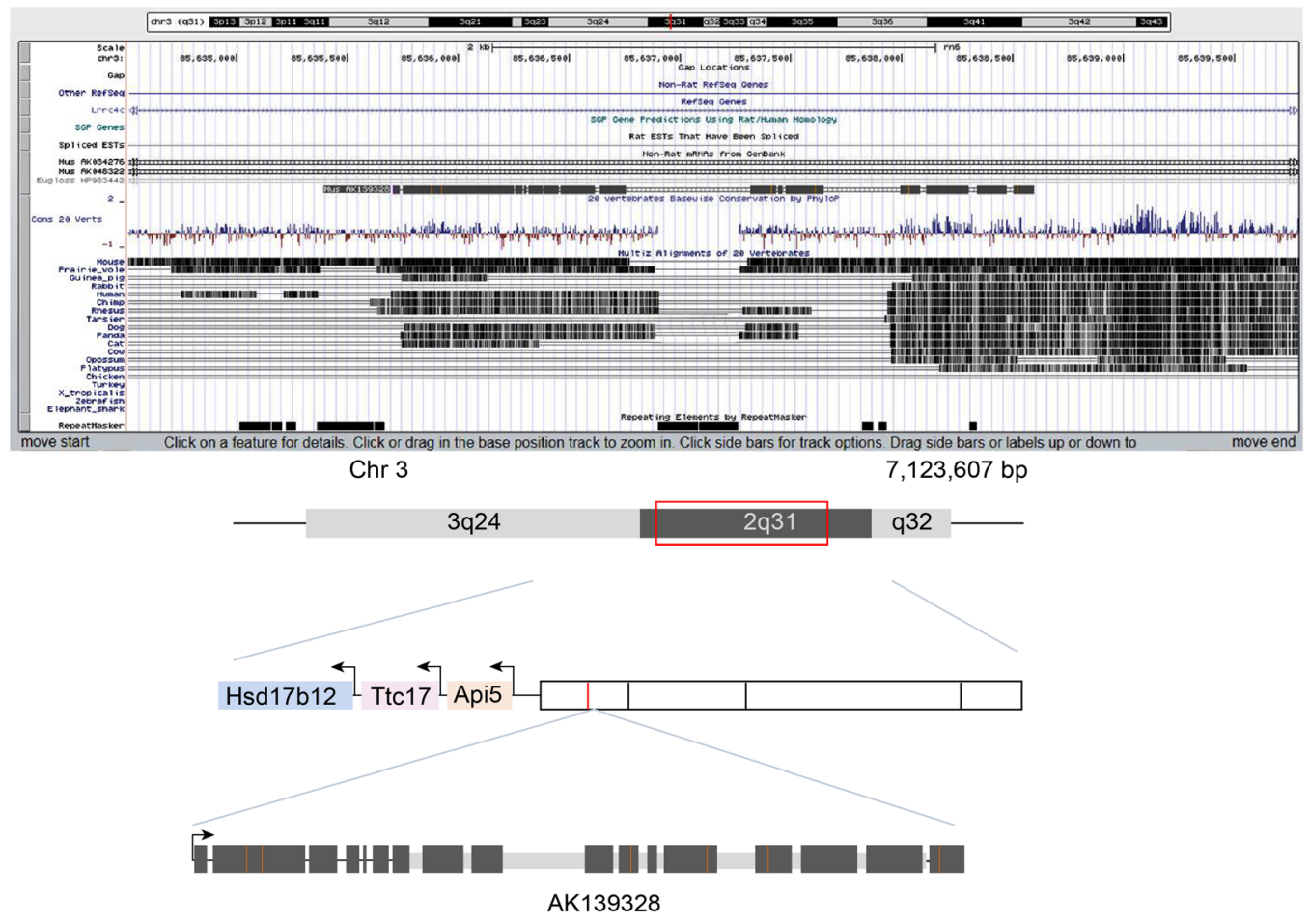

Figure 2: Chromosomal localization of rat IncRNA AK139328. 
cells were also observed attached to the VECs (Figure 12). The negative controls showed uniformly arranged muscle fibers with normal cell morphology, uniform size, intercellular space and vascular endothelial structure in the vascular wall. The VECs were flat, normal-sized, regularly arranged and closely attached to the inner lumen of internal elastic membrane with the nucleus protruding into the lumen. VECs did not show any swelling and were not associated with any inflammatory cells. In the I/R + si-AK139328 group, muscle fibers were slightly swollen and unevenly sized but regularly arranged. No dissolution and fracture was found in the fibers. Some muscle cells showed slight swelling, intercellular space and fractures. VECs were regularly arranged although some were swollen. They were closely attached to the internal elastic membrane, with few VECs found in the lumen and few attached to inflammatory cells. In the I/R + Wortmannin group, the fiber swelling was more severe than the I/R group. The fibers were irregularly arranged, twisted, and fractured. Muscle tissues showed severe swelling, narrow

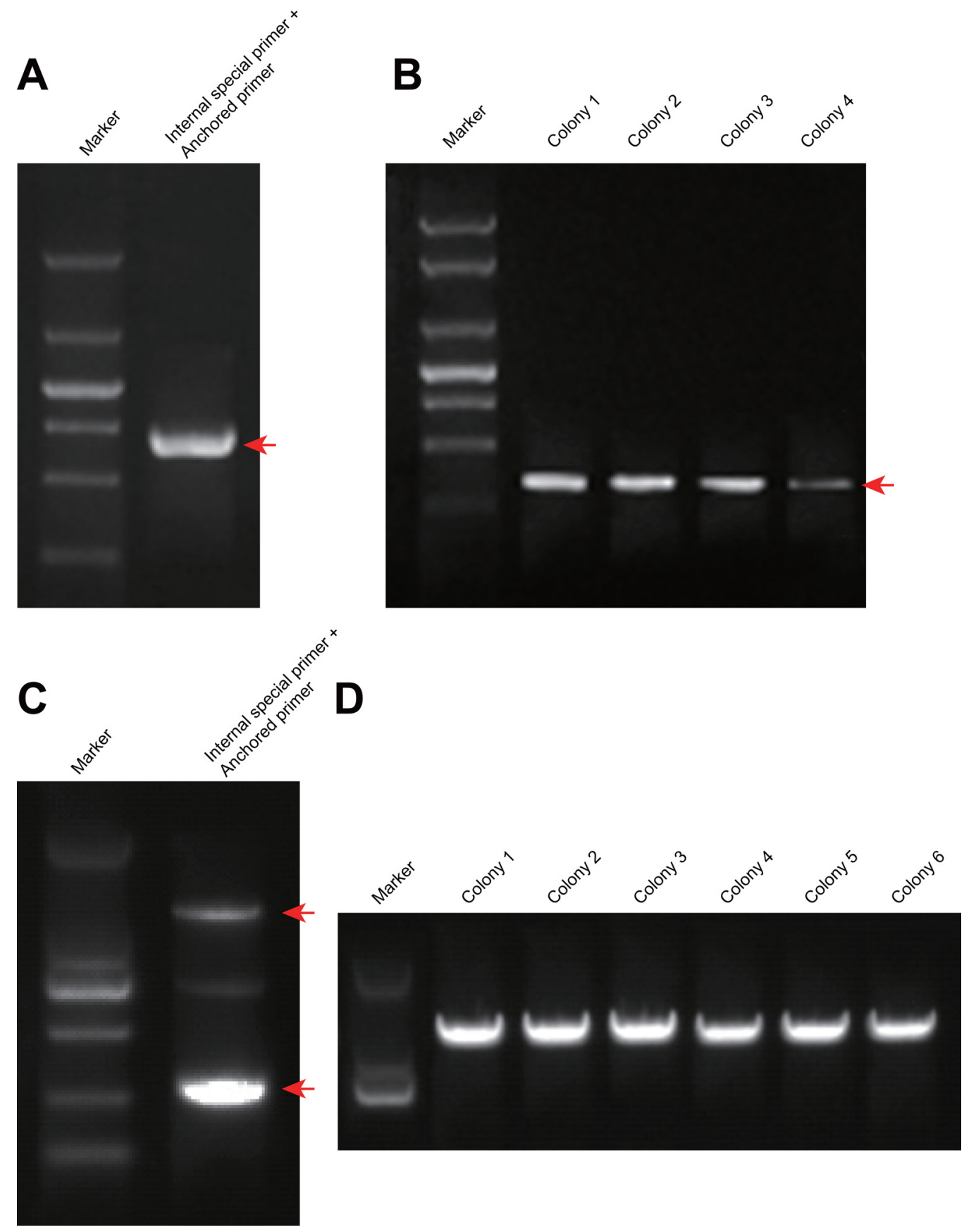

Figure 3: Cloning and analysis of full length rat IncRNA AK139328 by $\mathbf{3}^{\prime}$ and $5^{\prime}$ RACE. Representative agarose gel showing (A) 3' RACE amplified rat lncRNA AK139328 transcript; (B) Identification of positive clones of 3'RACE rat lncRNA AK139328 partial product by colony PCR; (C) 5' RACE amplified rat lncRNA AK139328 transcript; (D) Identification of positive clones of entire lncRNA AK139328 transcript by colony PCR. 


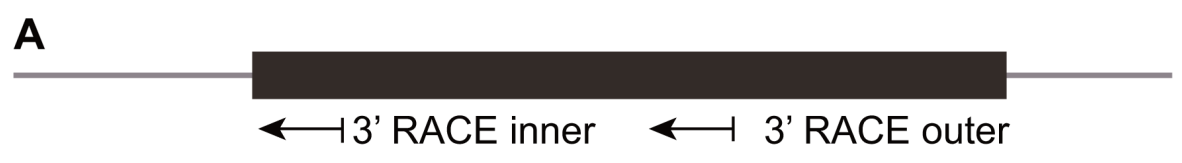

B

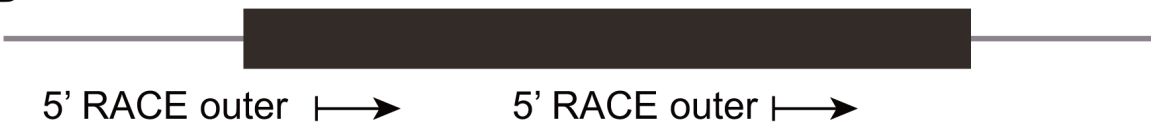

C

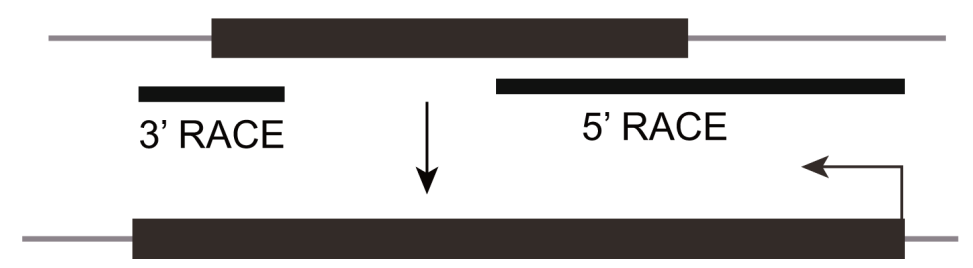

Figure 4: The binding sites of 3' RACE and 5' RACE on both side of the primers and full length nucleotide sequence of rat IncRNA AK139328. (A) The binding sites of 3 'RACE on both side of the primers; (B) The binding sites of 5' RACE on both side of the primers; (C) full length nucleotide sequence of rat lncRNA AK139328; QPCR forward primer binds to the 1725-1744 base position, and reverse primer binds to the $1884-1903$ base position.

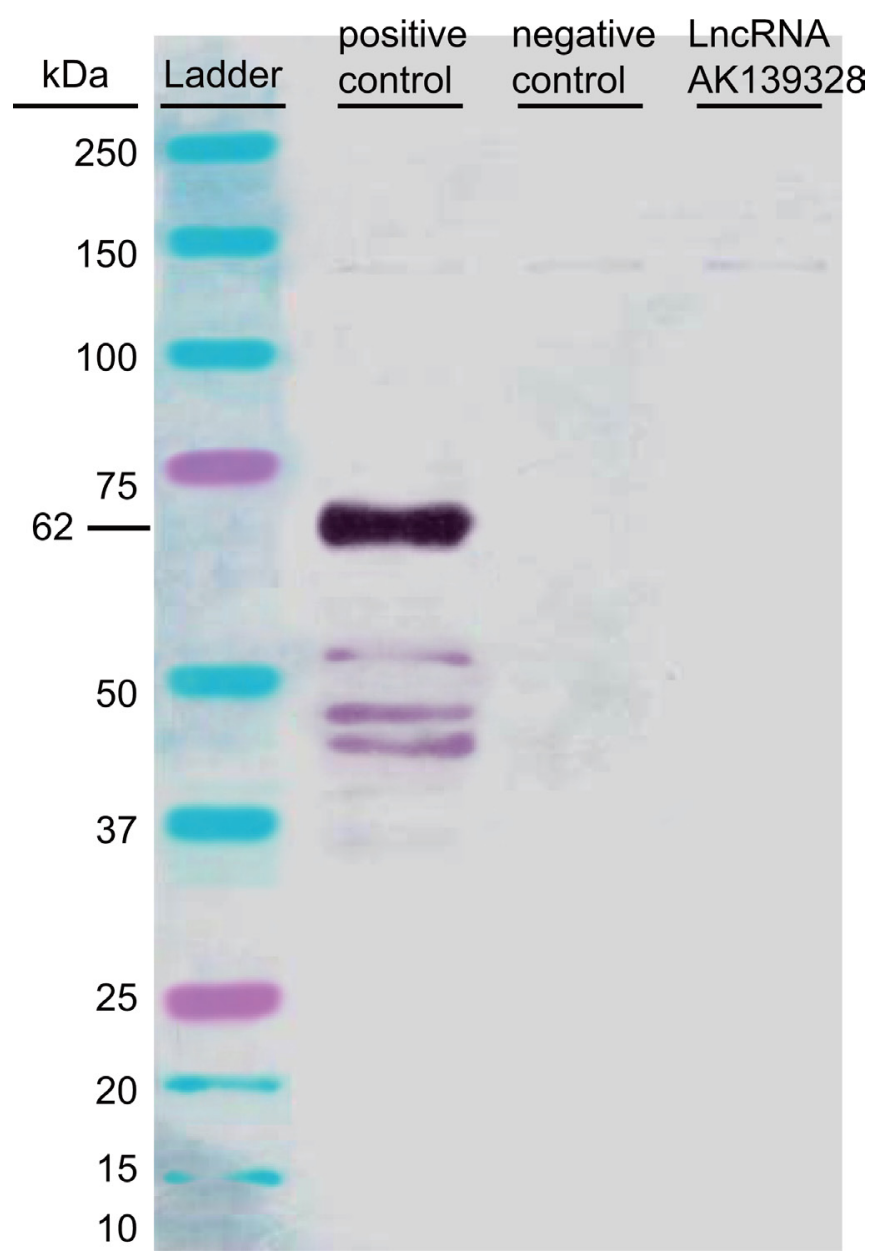

Figure 5: In vitro transcription \& translation of cloned rat IncRNA AK139328. SDS-PAGE analysis showing in vitro transcribed and translated products of positive control $(62 \mathrm{kDa})$, no template negative control and lncRNA AK 139328. Note: (L) Protein ladder. 
Table 1: p-Akt/Akt and p-PI3K/PI3K ratio changes of cells in each group

\begin{tabular}{|l|l|l|l|}
\hline Group & p-Akt/Akt & \multicolumn{1}{l}{ p-PI3K/ PI3K } & \multicolumn{1}{l}{ ROS } \\
\hline Control & $0.81 \pm 0.04$ & $0.80 \pm 0.06$ & $65.5 \pm 7.1$ \\
\hline Model & $0.52 \pm 0.04^{*}$ & $0.52 \pm 0.05^{*}$ & $42.1 \pm 5 \cdot 2^{*}$ \\
\hline Model + si-AK139328 NC & $0.54 \pm 0.01^{*}$ & $0.53 \pm 0.01^{*}$ & $40.6 \pm 2.5$ \\
\hline Model + si-AK139328 & $0.98 \pm 0.01^{* \#}$ & $0.97 \pm 0.04^{* \#}$ & $112.3 \pm 7.1^{* *}$ \\
\hline Model + si-AK139328 + LY294002 & $0.55 \pm 0.07^{*}$ & $0.50 \pm 0.08^{*}$ & $42.1 \pm 5 \cdot 2^{*}$ \\
\hline Model + LY294002 & $0.35 \pm 0.06^{* \#}$ & $0.36 \pm 0.03^{* \#}$ & $25.7 \pm 2.5^{* \#}$ \\
\hline
\end{tabular}

Notes: ", compared with the control group, $P<0.05$; \#, compared with the model group, $P<0.05$; the experiment was repeated for four times and differences between groups were analyzed by $t$-test.

Table 2: p-Akt/Akt and p-PI3K/PI3K ratio changes in gastrocnemius muscle tissues in rats

\begin{tabular}{|l|l|l|l|l|}
\hline \multicolumn{1}{l}{ Group } & p-Akt/Akt & p-PI3K/PI3K & peNOS/eNOS & \multicolumn{1}{l}{ ROS } \\
\hline WT & $0.78 \pm 0.14$ & $0.76 \pm 0.08$ & $0.48 \pm 0.05$ & $78.2 \pm 14.5$ \\
\hline Sham & $0.75 \pm 0.04$ & $0.75 \pm 0.09$ & $0.47 \pm 0.04$ & $75.6 \pm 13.4$ \\
\hline I/R & $0.52 \pm 0.03^{*}$ & $0.58 \pm 0.09^{*}$ & $0.41 \pm 0.04^{*}$ & $56.5 \pm 5 .^{*}$ \\
\hline I/R+si-AK139328 NC & $0.52 \pm 0.01^{*}$ & $0.52 \pm 0.03^{*}$ & $0.38 \pm 0.03^{*}$ & $52.3 \pm 5.3^{*}$ \\
\hline Sham+si-AK139328 & $0.99 \pm 0.06^{* \#}$ & $0.90 \pm 0.03^{* \#}$ & $0.58 \pm 0.01^{* \#}$ & $142.1 \pm 18.5^{* \#}$ \\
\hline I/R+si-AK139328 & $1.19 \pm 0.09^{* \#}$ & $0.89 \pm 0.03^{* \#}$ & $0.61 \pm 0.01^{* \#}$ & $165.2 \pm 21.6^{* \#}$ \\
\hline I/R+si-AK139328+Wom & $0.57 \pm 0.12^{*}$ & $0.55 \pm 0.10^{*}$ & $0.39 \pm 0.05^{*}$ & $49.2 \pm 4.0^{*}$ \\
\hline I/R+Wom & $0.35 \pm 0.06^{* \#}$ & $0.33 \pm 0.07^{* \#}$ & $0.27 \pm 0.01^{* \#}$ & $29.2 \pm 2.9^{* \#}$ \\
\hline
\end{tabular}

Notes: ", compared with the sham group, $P<0.05$; , compared with the I/R group, $P<0.05$; 64 rats were included in the experiment ( 8 in each group) and differences between groups were analyzed by $t$-test; Wom, wortmannin; I/R, ischemiareperfusion.

intercellular space and loosely arranged vascular wall layers. VECs were swollen and loosely attached to the internal elastic membrane with nucleus protruding into the lumen and associated with many inflammatory cells. This demonstrated that PI3K/Akt signaling pathway was necessary for protecting the integrity and organization of the muscle fibers and VECs during I/R (Figure 12). Electron micrographs showed large lipid vacuoles in the I/R group, but fewer lipid vacuoles in the I/R + siAK139328 group (Figure 13).

\section{Role of IncRNA AK139328 in the pathology in rat hindlimb $\mathrm{I} / \mathrm{R}$ model}

Next, we analyzed the various pathological indicators in the rat hindlimb I/R model. Pro-inflammatory cytokines, TNF- $\alpha$ and VCAM-1 levels were higher in the I/R groups, but reduced upon IncRNA AK139328 silencing $(P<0.05$; Table 3$)$. This demonstrated that $\mathrm{I} / \mathrm{R}$ induced inflammation was PI3K/Akt dependent. Serum MDA levels and CK activity were higher in gastrocnemius muscle from $\mathrm{I} / \mathrm{R}$ rats, but were lowered by silencing lncRNA AK139328 $(P<0.05$; Table 4$)$. Moreover, there were high numbers of serum CECs in I/R rats, but reduced by silencing IncRNA AK139328 $(P<0.05$; Table 5). TUNEL assay showed increased apoptosis in gastrocnemius muscle upon $\mathrm{I} / \mathrm{R}$, but decreased upon lncRNA AK139328 silencing $(P<0.05$; Figure 14). However, inhibition of PI3K/AKT pathway by wortmannin reversed the effects of IncRNA AK139328 silencing. This suggested that activation of the PI3K/AKT signaling pathway was required to repair from $\mathrm{I} / \mathrm{R}$ injury.

\section{DISCUSSION}

In this study, we demonstrated that IncRNA AK139328 negatively regulated the PI3K/Akt signaling pathway in I/R injury. LncRNAs are a class of noncoding RNAs, more than 200 nucleotides in length that regulate gene expression at transcriptional and posttranscriptional levels as well as chromatin modification and genomic imprinting [19]. LncRNA CRNDE promotes the proliferation, migration and invasiveness of hepatocellular carcinoma (HCC) cells [20]. LncRNA EWSAT1 promotes human nasopharyngeal carcinoma cell growth [21]. Thus, lncRNAs play pivotal roles in regulating a wide range of biological processes and are critical in various diseases [22].

In a previous study, LY294002, a PI3K inhibitor, repressed the expression of thrombin-activating fibrinolysis inhibitor (TAFI) in human hepatoma HepG2 Cells by decreasing the stability of $\mathrm{CPB} 2$ transcripts [23]. Akt is activated as a protective mechanism against 
liver I/R injury $[15,24]$. Metastasis-associated lung adenocarcinoma transcript 1 (MALAT1) suppresses tumor growth and metastasis by activating the PI3K/Akt signaling pathway in I/R injury [25]. Silencing of lncRNA urothelial carcinoma associated 1 (UCA1) regulates cell cycle progression by enhancing Akt signaling in bladder carcinoma cells [26]. LncRNA AK139328 knockdown increases Akt levels in mouse livers after hepatic I/R [17]. This suggests that lncRNA AK139328 negatively regulates the PI3K/Akt signaling pathway. ROS and PI3K/Akt signaling pathway co-ordinately regulate the malignancy of 4-hydroxy estradiol (4-OH-E2)-transformed mammary epithelial cells by regulating the expression of many cell cycle related genes and related transcription factors [27].
We also demonstrated that lncRNA AK139328 knockdown decreased TNF- $\alpha$ and VCAM-1 expression by activating the PI3K/Akt signaling pathway. Endothelial progenitor cells (EPCs) are inhibited by TNF- $\alpha$, but impaired EPCs proliferation is reversed by berberine via the PI3K/Akt/eNOS signaling pathway [28]. Jung et al. showed that pre-treatment with PI3K inhibitors decreased TNF- $\alpha$ levels in EPCs [29]. TNF- $\alpha$-induced inflammation is inhibited by downregulation of the PI3K/Akt signaling pathway in human umbilical vein endothelial cells [30]. Phosphotase and tensin homolog (PTEN) regulates VCAM-1 levels by suppressing PI3K/Akt signaling in TNF- $\alpha$-activated human endothelial cells [31]. PI3K/ Akt pathway activated by $\alpha$-lipoic acid (LA) attenuates
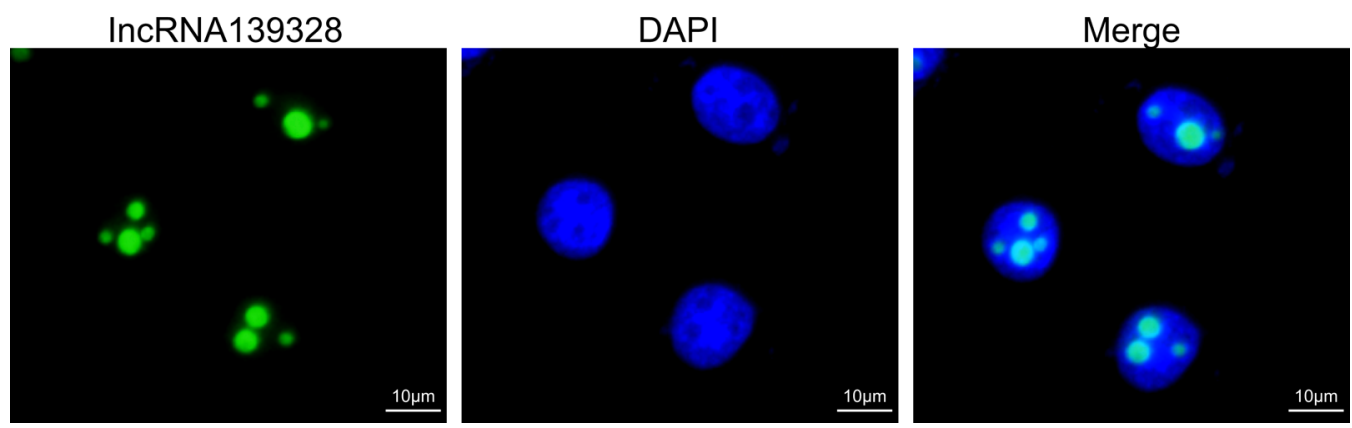

Figure 6: RNA FISH analysis of IncRNA AK139328 in rat VECs. Representative images $(200 \times)$ showing lncRNA AK139328 transcripts in the nucleus of rat VECs.

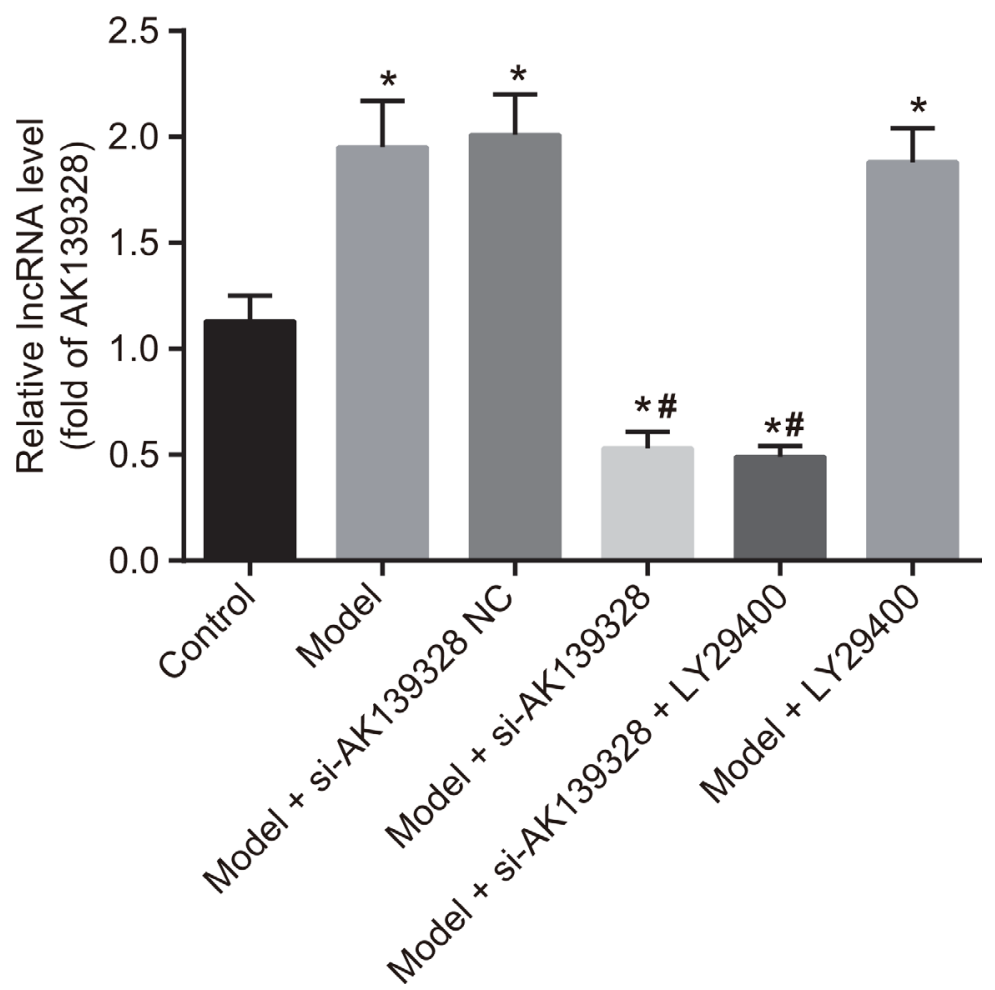

Figure 7: Quantitative RT-PCR analysis of IncRNA AK139328 in rat VECs. Histogram plots show lncRNA AK139328 levels in (1) control, (2) model, (3) model + si AK139328 NC, (4) model + siAK139328, (5) model + si-AK139328 + LY294002, and (6) model + LY294002 groups of rats VECs. Note: ${ }^{*}$ denotes $P<0.05$ compared with the control group; ${ }^{*}$ denotes $P<0.05$ compared with the model group. The experiment was repeated four times and analyzed by $t$-test. 
A

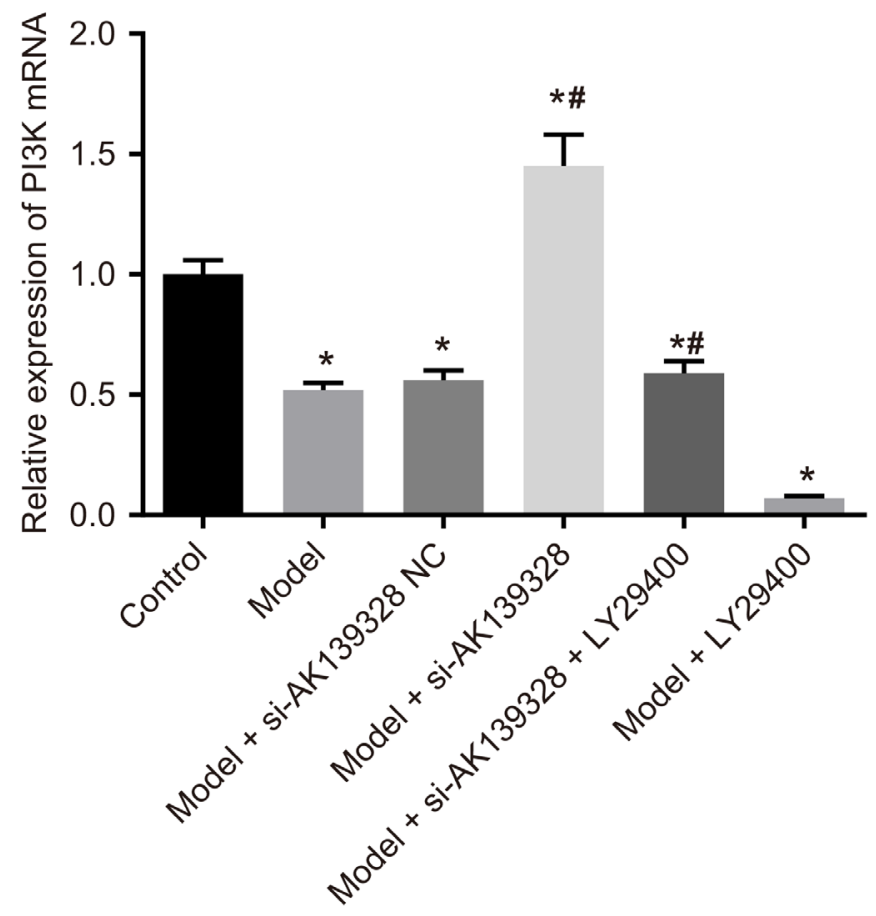

C

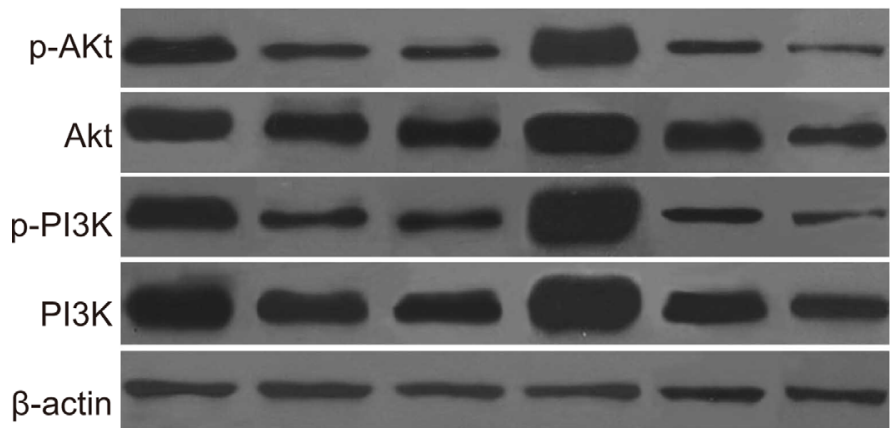

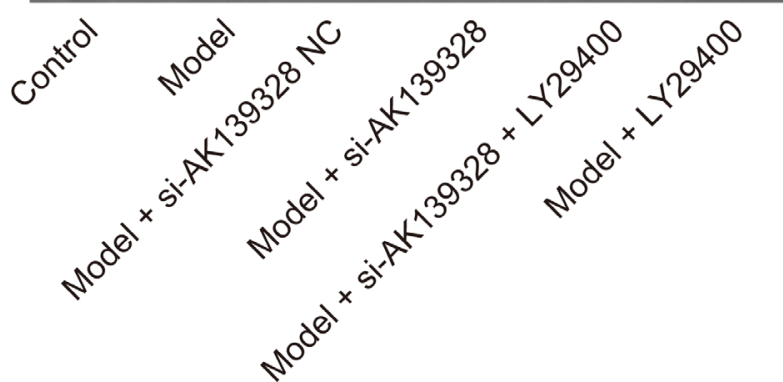

B

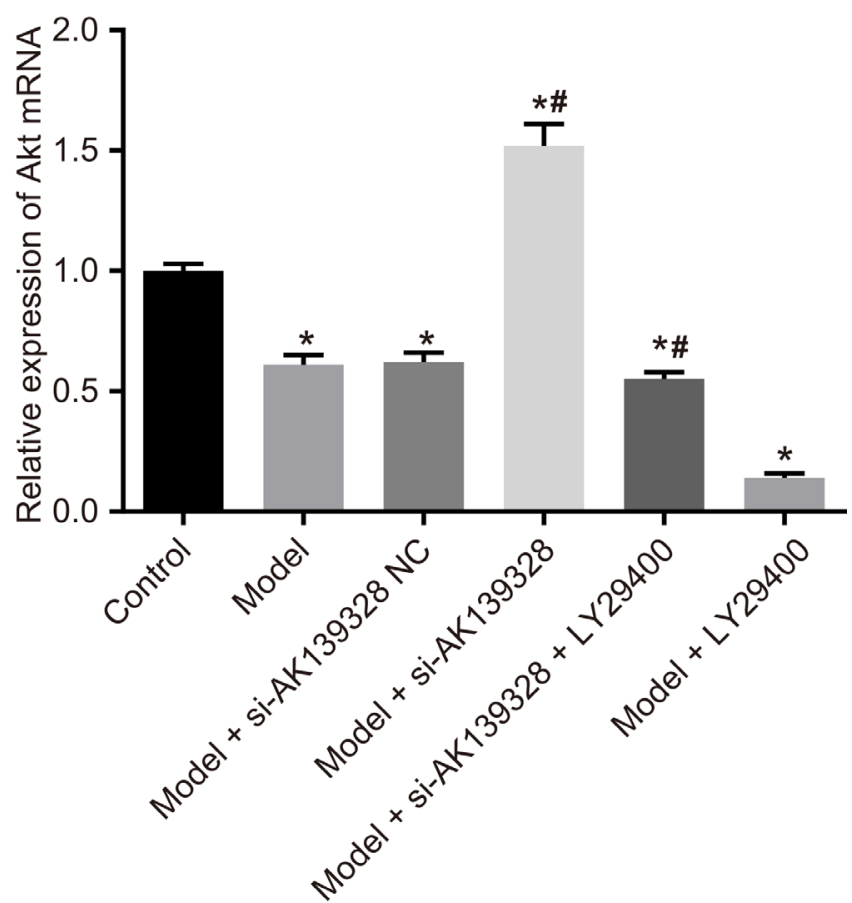

D

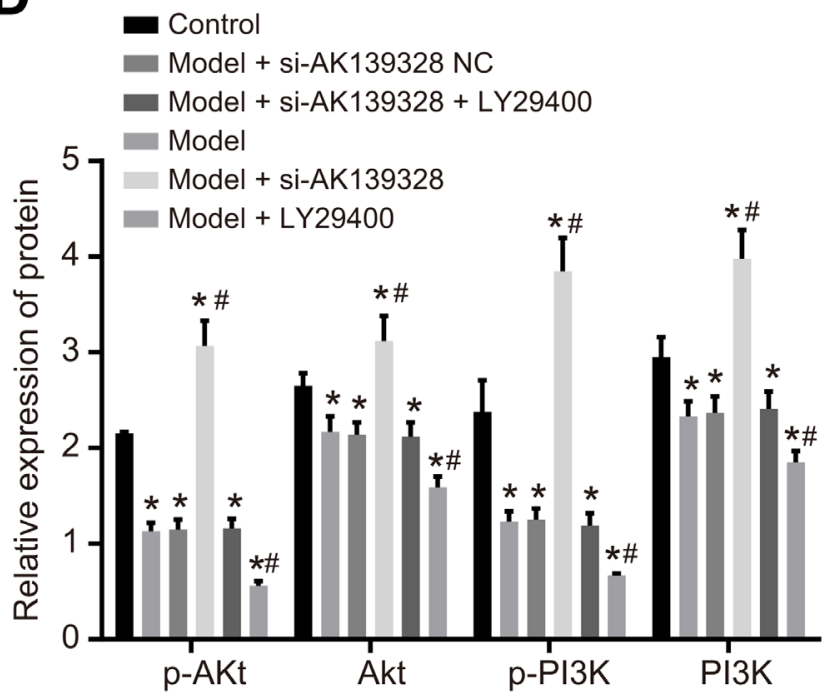

Figure 8: QRT-PCR and Western blot analysis of PI3K/Akt signaling pathway in rat VECs subjected to I/R. (A-B) QRTPCR analysis of (A) PI3K and (B) Akt mRNA levels in (1) control, (2) model, (3) model + si AK139328 NC, (4) model + siAK139328, (5) model + si-AK139328 + LY294002, and (6) model + LY294002 groups of rats VECs subjected to I/R. $\beta$-actin was used as internal control. (C-D) Representative Western blots showing levels of total and phosphorylated (C) PI3K and (D) Akt proteins in rat VECs groups 1-6 subjected to I/R. GAPDH was used as control. Note: * denotes $P<0.05$ compared with control group; ${ }^{*}$ denotes $P<0.05$ compared with model group; the experiment was repeated four times and analyzed by $t$-test. LY294002 $=$ PI3K/AKT signaling pathway inhibitor; si-AK139328 NC = negative control siRNA; si-AK139328 = siRNA against lncRNA AK139328. 
Table 3: Changes of inflammatory cytokines TNF- $\alpha$ and VCAM in rats by ELISA

\begin{tabular}{|l|l|l|}
\hline \multicolumn{1}{l|}{ Troup } & TNF- $\boldsymbol{\alpha}(\mathbf{n g} / \mathbf{L})$ & VCAM-1 $(\boldsymbol{\mu g} / \mathbf{L})$ \\
\hline WT & $28.16 \pm 1.85$ & $235.52 \pm 19.43$ \\
\hline Sham & $27.95 \pm 1.96$ & $242.52 \pm 20.25$ \\
\hline I/R & $48.01 \pm 5.85^{*}$ & $354.78 \pm 26.75^{*}$ \\
\hline I/R + si-AK139328 NC & $42.97 \pm 4.77^{*}$ & $350.71 \pm 24.08^{*}$ \\
\hline Sham + si-AK139328 & $22.01 \pm 2.15^{* \#}$ & $195.65 \pm 10.84^{* \#}$ \\
\hline I/R + si-AK139328 & $35.05 \pm 1.55^{* \#}$ & $300.25 \pm 18.74^{* \#}$ \\
\hline I/R + si-AK139328+ Wom & $44.95 \pm 1.97^{*}$ & $349.88 \pm 20.52^{*}$ \\
\hline I/R + Wom & $65.18 \pm 3.99^{* \#}$ & $395.58 \pm 21.05^{* \#}$ \\
\hline
\end{tabular}

Notes: *, compared with the sham group, $P<0.05$; *, compared with the I/R group, $P<0.05$; 64 rats were included in the experiment ( 8 in each group) and differences between groups were analyzed by $t$-test; Wom, wortmannin; I/R, ischemiareperfusion.

inflammatory response by activating PI3K/Akt pathway, which decreases VCAM-1 levels; inhibition of the PI3K/ Akt signaling by wortmannin abolishes LA-induced protection in myocardium [32]. Wortmannin abolished the protective effect of PI3K/Akt signaling pathway activation in cardiac dysfunction because of high HSPA12B expression, which decreases VCAM-1 levels [33]. In this study, lncRNA AK139328 inhibits the PI3K/Akt signaling pathway, but, wortmannin decreases inflammatory cytokines, TNF- $\alpha$ and VCAM-1 by down-regulating the PI3K/Akt signaling pathway. This suggests that silencing lncRNA AK139328 suppresses
TNF- $\alpha$ and VCAM-1 by activating the PI3K/Akt signaling pathway.

I/R injury causes tissue damage, complement activation, cytochrome release, cytokine activation, inflammation, edema, neutrophil platelet adhesion, capillary plugging, and thrombosis [34]. Spinal cord ischemia triggered local edema, vasospasm, free radicals, calcium influx into the axons, and loss of potassium from the intercellular space [35]. In our study, silencing lncRNA AK139328 inhibited edema, dissolution, muscle fiber damage (fracture and swelling) and association of immune cells to VECs in response to I/R injury. We also observed decreased MDA levels and CK activity in the plasma.

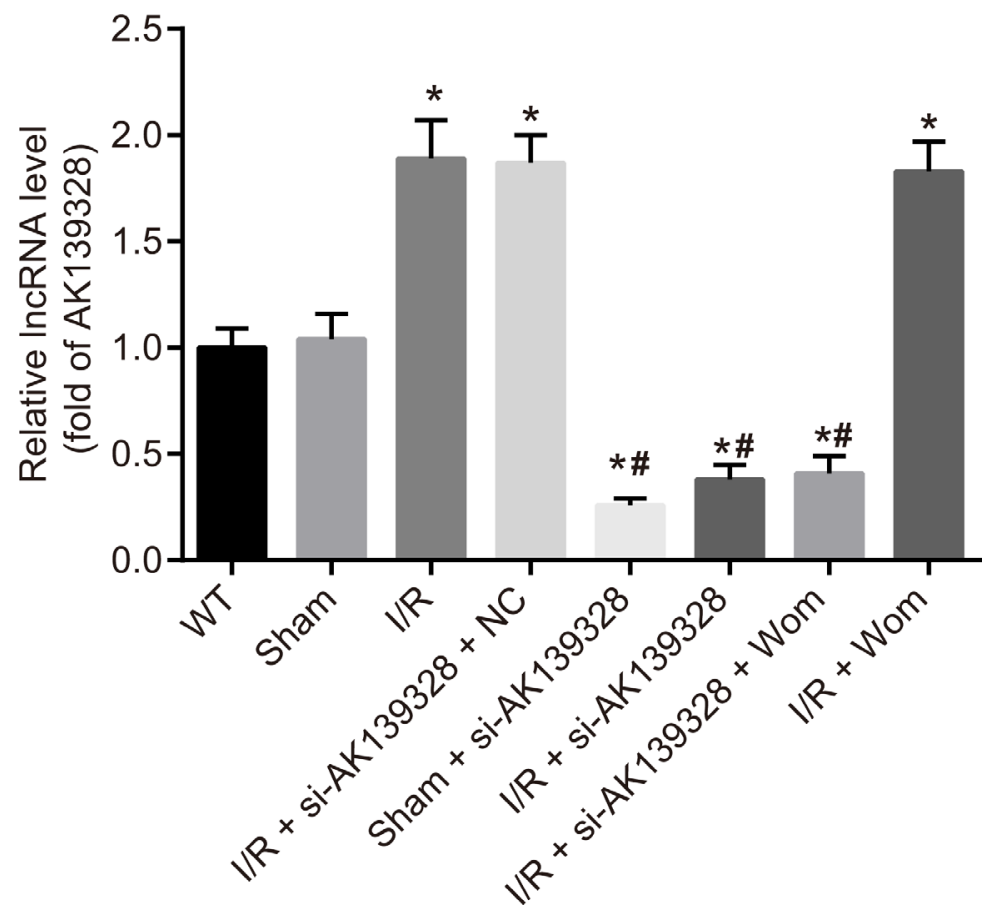

Figure 9: LncRNA AK139328 levels in gastrocnemius muscle of rats subjected to I/R injury. QRT-PCR analysis of lncRNA AK139328 levels in gastrocnemius muscles of rats belonging to (1) WT (2) I/R (3) sham (4) I/R + si-AK139328 NC (5) sham + siAK139328 (6) I/R + si-AK139328 (7) I/R + si-AK139328 + Wom and (8) I/R + Wom groups ( $n=8$ per group). $\beta$-actin was used as internal control. Note: ${ }^{*}$ denotes $P<0.05$ compared with sham group; ${ }^{*}$ denotes $P<0.05$ compared with $\mathrm{I} / \mathrm{R}$ group; the experiment was analyzed by $t$-test; Wom = wortmannin; si-AK139328 NC = negative control siRNA; si-AK139328 = siRNA against lncRNA AK139328. 
Table 4: The serum MDA concentration and CK viability in rats among the eight groups

\begin{tabular}{|l|l|l|}
\hline Group & MDA $(\mathbf{n m o l} / \mathbf{m l})$ & CK $(\mathbf{U} / \mathbf{m l})$ \\
\hline WT & $8.01 \pm 0.76$ & $0.51 \pm 0.17$ \\
\hline Sham & $7.96 \pm 0.87$ & $0.55 \pm 0.19$ \\
\hline I/R & $24.28 \pm 2.31^{*}$ & $1.42 \pm 0.32^{*}$ \\
\hline I/R + siAK139328 NC & $23.97 \pm 2.46^{*}$ & $1.39 \pm 0.13^{*}$ \\
\hline Sham + si-AK139328 & $4.98 \pm 0.32^{* \#}$ & $0.15 \pm 0.03^{* \#}$ \\
\hline I/R + siAK139328 & $19.18 \pm 1.68^{* \#}$ & $0.95 \pm 0.09^{* \#}$ \\
\hline I/R + siAK139328 + Wom & $24.76 \pm 2.39^{*}$ & $1.47 \pm 0.30^{*}$ \\
\hline I/R + Wom & $28.47 \pm 2.61^{* \#}$ & $1.96 \pm 0.29^{* \#}$ \\
\hline
\end{tabular}

Notes: ", compared with the sham group, $P<0.05$; \#, compared with the $\mathrm{I} / \mathrm{R}$ group, $P<0.05$; 64 rats were included in the experiment ( 8 in each group) and differences between groups were analyzed by $t$-test; Wom, wortmannin; $\mathrm{I} / \mathrm{R}$, ischemiareperfusion; MDA, Malondialdehyde; $\mathrm{CK}$, creatine kinase.

Moreover, silencing lncRNA AK139328 decreased the presence of CECs in the serum and apoptosis in the gastrocnemius muscle cells by inhibiting the PI3K/Akt signaling pathway. The number of serum CECs indicates the severity of acute respiratory distress syndrome [36]. In cancer patients, CECs are shed from vessel walls and enter circulation as a result of endothelial dysfunction and correlates with tumor progression [37]. Treatment with
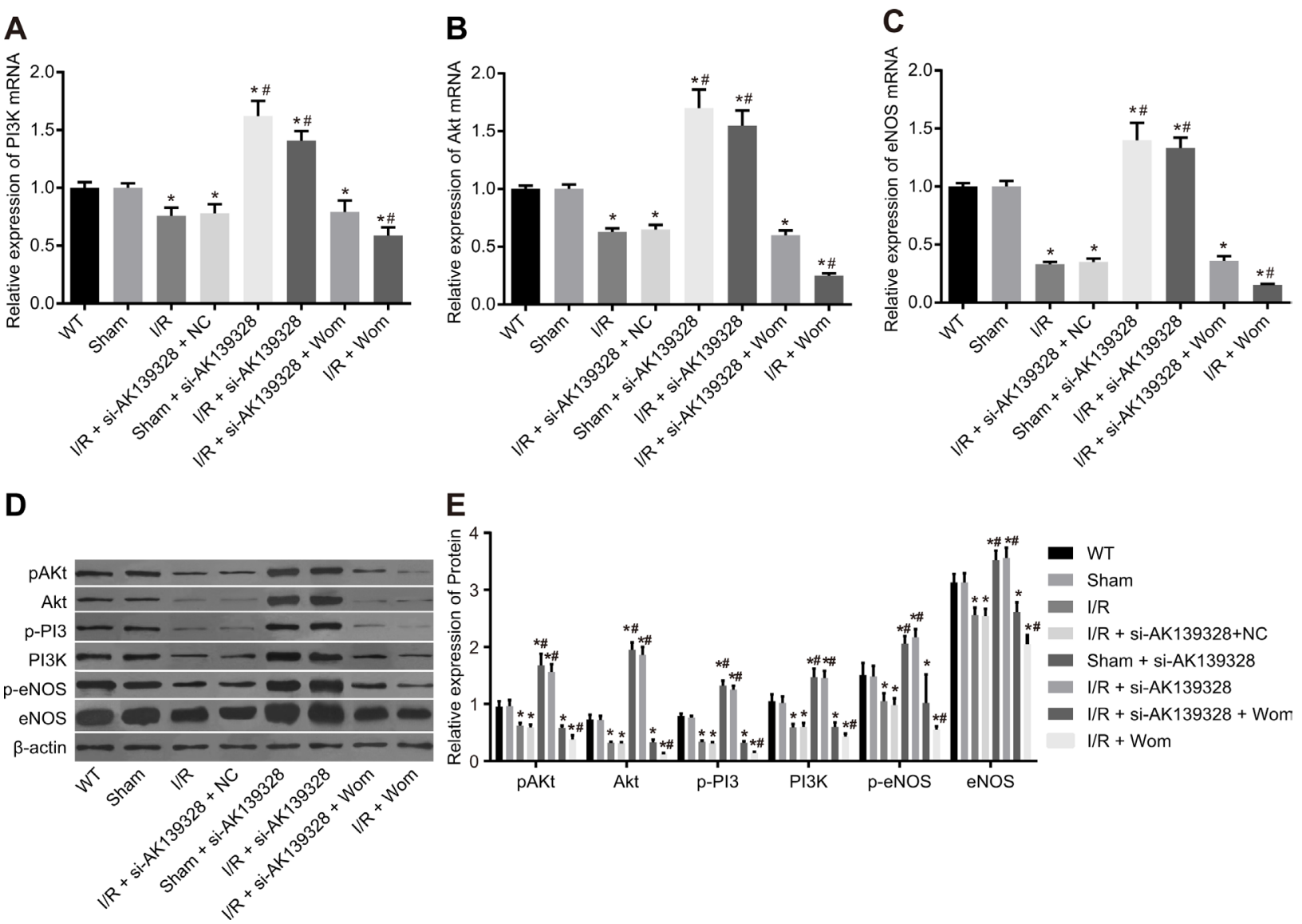

Figure 10: Analysis of PI3K/Akt/eNOS signaling in gastrocnemius muscles of rats subjected to I/R. (A-C) QRT-PCR analysis of (A) PI3K (B) Akt and (C) eNOS mRNA levels in the gastrocnemius muscles of (1) WT (2) I/R (3) sham (4) I/R + si-AK139328 $\mathrm{NC}$ group (5) sham + si-AK139328 (6) I/R + si-AK139328 group (7) I/R + si-AK139328 + Wom group and (8) I/R + Wom group rats $(n=8$ per group). $\beta$-actin was used as internal control. (D) Representative Western blots showing levels of total and phosphorylated PI3K, Akt and eNOS proteins in gastrocnemius muscles of rat groups 1-8 in the hindlimb I/R model. GAPDH was used as control. (E) Histograms showing the levels of total and phosphorylated PI3K, Akt and eNOS proteins in gastrocnemius muscles of rat groups 1-8 in the hindlimb I/R model. Note: ${ }^{*}$ denotes $P<0.05$ compared with sham group; ${ }^{*}$ denotes $P<0.05$ compared with I/R group; the experiment was analyzed by $t$-test. Wom = wortmannin; 
Table 5: Number of serum CECs in rats among the eight groups

\begin{tabular}{|l|l|}
\hline Group & Number of CECs $(\mathbf{n} / \mathbf{0 . 9}$ ul) \\
\hline WT & $2.87 \pm 0.28$ \\
\hline Sham & $2.83 \pm 0.26$ \\
\hline I/R & $8.79 \pm 0.85^{*}$ \\
\hline I/R + si-AK139328 NC & $8.91 \pm 0.78^{*}$ \\
\hline Sham + si-AK139328 & $1.75 \pm 0.19^{* \#}$ \\
\hline I/R + si-AK139328 & $4.48 \pm 0.43^{* \#}$ \\
\hline I/R + si-AK139328 + Wom & $8.81 \pm 0.84^{*}$ \\
\hline I/R + Wom & $12.57 \pm 1.05^{* \#}$ \\
\hline
\end{tabular}

Notes: *, compared with the sham group, $P<0.05$; \#, compared with the $\mathrm{I} / \mathrm{R}$ group, $P<0.05$; 64 rats were included in the experiment ( 8 in each group) and differences between groups were analyzed by $t$-test; Wom, wortmannin; $\mathrm{I} / \mathrm{R}$, ischemiareperfusion; CECs, circulating endothelial cells.

antioxidant $\mathrm{N}$-acetyl cysteine reduced $\mathrm{I} / \mathrm{R}$ injury in the femoral artery endothelium and gastrocnemius muscle by preventing tissue damage and gastrocnemius muscle apoptosis [38]. We demonstrated that silencing lncRNA AK139328 protected VECs, decreased the serum CECs and apoptotic gastrocnemius muscle cells via PI3K/Akt signaling pathway.

In conclusion, our findings suggest that silencing lncRNA AK139328 enhances survival and limits pathological damage to VECs due to $\mathrm{I} / \mathrm{R}$ injury by activating the PI3K/Akt signaling pathway. Hence, lncRNA AK139328 is a potential target in I/R therapy. may be a potential biomarker for treatment of VECs injury caused by $\mathrm{I} / \mathrm{R}$. But more underlying molecular mechanism studies are in need to verify the result and explore the further potentials.

\section{MATERIALS AND METHODS}

\section{Cloning and analysis of rat IncRNA AK139328}

We searched the rat genome database in GenBank by BLAST program [39] (taxid: 10116) (http://blast.ncbi. nlm.nih.gov/) using the full-length nucleotide sequence of mouse IncRNA AK139328 (full length of mouse AK139328 sequence is available at http://www.ncbi.nlm.nih.gov/ nuccore/AK139328). We determined homology between the nucleotide sequences of mice and rat lncRNA AK139328.

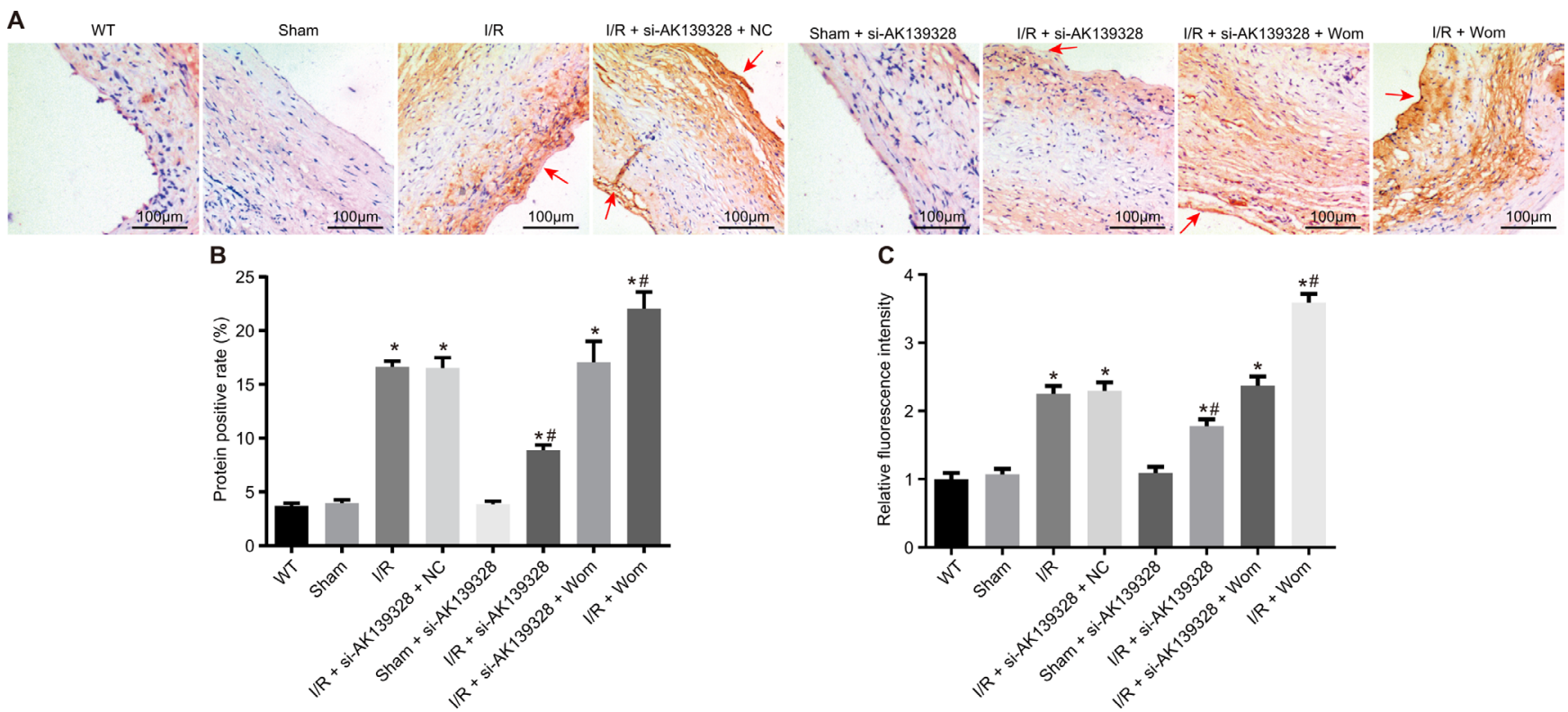

Figure 11: Immunohistochemical analysis of caspase-3 in gastrocnemius muscles of rats subjected to I/R. (A) Representative images $(200 \times)$ showing immunohistochemical $(\mathrm{IHC})$ staining of caspase- 3 in gastrocnemius muscle sections from rat groups 1-8 is shown. Arrows indicate the positive expression of caspase-3. (B) Quantitative analysis of caspase-3 expression in IHC stained gastrocnemius muscle sections from rat groups 1-8 ( $n=8$ /group). (C) Quantitative analysis of caspase-3 viability in IHC stained gastrocnemius muscle sections from rat groups $1-8$ ( $n=8$ /group). Note: * denotes $P<0.05$ compared with sham group; $\#$ denotes $P<0.05$ compared with I/R group; the experiment was analyzed by $t$-test. 
To clone full length lncRNA AK139328, we isolated total RNA from rat VECs by the method of Trizol. Then, we used the reverse transcription kit to generate cDNA and performed 3'RACE by nested-PCR (3'RACE Inner Primer: GTGGCCCCTTGGTCTTGCAAAC, 3'RACE Outer Primer: GTGTCTGCAACCCGATAGGT). First, PCR was performed with the lateral primers. The PCR products were diluted 100 times and then the second round of PCR was performed. After the second round of PCR, the PCR products were electrophoresed in a $1 \%$ agarose gel, purified, cloned and sequenced.

For the 5' RACE, RNA was incubated with calf intestinal phosphatase (CIP) at $37^{\circ} \mathrm{C}$ for $1 \mathrm{~h}$. After terminating the CIP reaction, the RNA was extracted with phenol-chloroform. Then, the RNA was incubated with tobacco acid pyrophosphatase (TAP) at $37^{\circ} \mathrm{C}$ for $1 \mathrm{~h}$ followed by incubation with the $5^{\prime} \mathrm{RACE}$ adapter at $37^{\circ} \mathrm{C}$ for $1 \mathrm{~h}$. Then, we performed reverse transcription using the $3^{\prime}$-RACE PCR product as a template and subjected the cDNA product to 5'RACE by nested PCR as described for $3^{\prime} \mathrm{RACE}$ (5'RACE Inner Primer: AGTTTGCAAGACCAAGGGGCCAC, 5'RACE Outer Primer: ACTATTATGTCAATATATAA).

\section{In vitro transcription \& translation}

We performed in vitro transcription and translation of the full-length rat lncRNA AK139328 cloned into pcDNA3.1 plasmid with the T7 promoter using the TnT quick transcription translation kit (Promega, Madison, WI, USA). Then, $1 \mu \mathrm{l}$ of the reaction product was boiled at $100^{\circ} \mathrm{C}$ for 2 min with $15 \mu \mathrm{L}$ SDS (sodium dodecyl sulfate) loading buffer and subjected to $4 \% \sim 12 \%$ NuPAGE SDSpolyacrylamide gel electrophoresis (Life Technologies Corporation, Carlsbad, CA, USA). Streptomycin affinity antibody was incubated with proteins labeled with biotinylated Transcend tRNA. Subsequently, the gel was placed in G250-10\% acetic acid and $-45 \%$ methanol, and after $4 \mathrm{~h}$ of greenhouse effect, it was washed twice and then photographed.RNA-FISH analysis in rat VECs

We generated a specific FISH fluorescent DyLight 488-labelled RNA probe (Promega, Madison, WI, USA) for the rat lncRNA AK139328. The rat VECs were grown on treated slides for $12 \sim 16 \mathrm{~h}$, washed twice with by 1 $\times$ PBST $(\mathrm{PBS}+0.1 \%$ Tween-20) followed by incubation at room temperature with $4 \%$ polyoxymethylene for 15 minutes. The cells were subsequently treated with $4 \mu \mathrm{g} /$ $\mathrm{ml}$ proteinase $\mathrm{K}$ for $5 \mathrm{~min}, 200 \mu \mathrm{l}$ glycine in $1 \times \mathrm{PBST}$ for 5 minutes, and $200 \mu \mathrm{l}$ of acetylation reagent for 10 minutes. Then, the slides were incubated with $200 \mu \mathrm{l}$ prehybridization solution at $65^{\circ} \mathrm{C}$ for $1 \mathrm{~h}$ followed by 300 $\mathrm{ng} / \mathrm{ml}$ probe in $200 \mu \mathrm{l}$ hybridization solution overnight at $65^{\circ} \mathrm{C}$ in a culture plate covered with paraffin wax. The hybridization solution was removed, and the slides were incubated serially with solutions 1,2 and 3, respectively at $65^{\circ} \mathrm{C}$ for 10 mins. Then, they were incubated with $300 \mu \mathrm{l} \quad 0.5 \%$ bovine serum albumin (BSA) at room temperature for $1 \mathrm{~h}$. Then, the slides were incubated with antibody diluted in $0.5 \%$ BSA at room temperature for 4 $\sim 5 \mathrm{~h}$, followed by DAPI (4',6-diamidino-2-phenylindole) staining at room temperature for $5 \mathrm{~min}$. The slides were sealed with antifade reagent and kept at $4^{\circ} \mathrm{C}$ before being photographed under an inverted fluorescent microscope (LWD300-38LFT, Shanghai Cewei Electrooptical

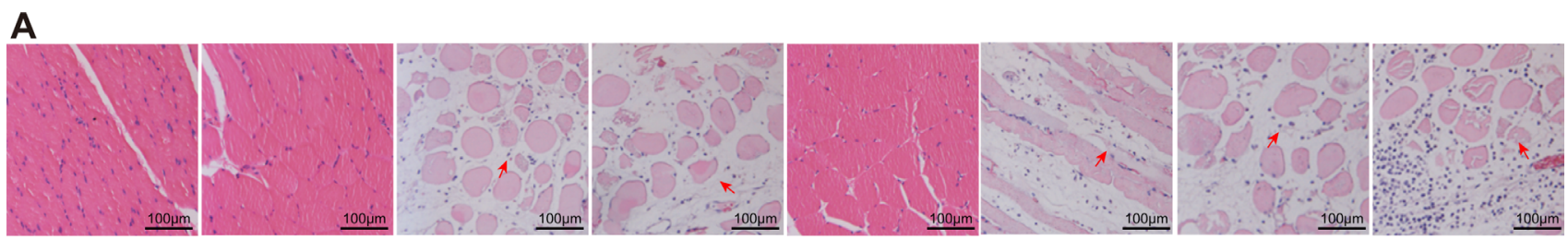

B

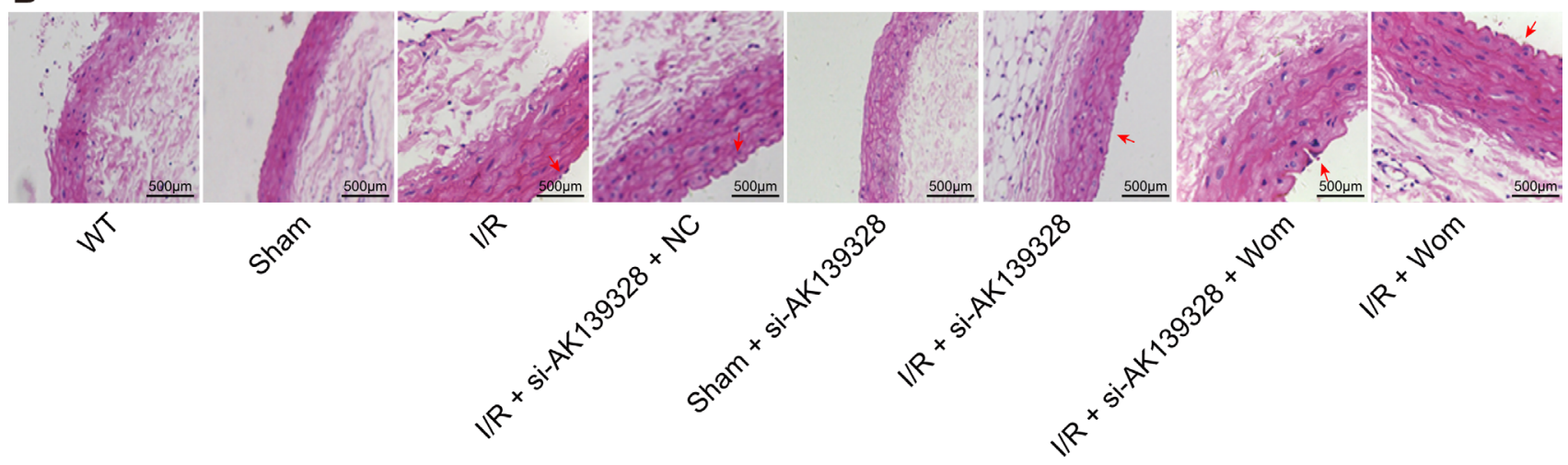

Figure 12: Histological analysis of H\&E stained skeletal muscle sections from rats subjected to I/R. (A) Representative images $(200 \times)$ of H\&E stained skeletal muscle sections from rat groups (1-8) in the hindlimb I/R model. Note: Arrows indicate the muscle fiber fracture at twisted positions. (B) Representative images $(40 \times)$ of H\&E stained vascular wall sections from rat groups $(1-8)$ in the hindlimb I/R model. The arrows indicate cellular edema and inflammatory cell adhesion; 64 rats were included in the experiment (8 in each group). 
Technology Co., Ltd., Shanghai, China) at $488 \mathrm{~nm}$ (DyLight 488) and at $<460 \mathrm{~nm}$.

\section{Experimental animals and grouping}

This study was approved by the Animal Care Committee of College of Animal Sciences, Zhejiang University. Adult male Wistar rats (weight: $200 \sim 250 \mathrm{~g}$ ) were obtained from the Institute of Animal Husbandry and Veterinary, Shanxi Academy of Agricultural Sciences (Taiyuan, China). Sixty-four rats were randomly assigned into 8 groups: WT (no treatment), I/R (no treatment after $\mathrm{I} / \mathrm{R}$ ), sham (injected with normal saline), I/R + si-AK139328 negative control (NC) (injected with siAK139328 NC after I/R), sham + si-AK139328 (injected with siAK139328 and normal saline), I/R + si-AK139328 (injected with siAK139328 after I/R), I/R + si-AK139328 + Wom (injected with siAK139328 and wortmannin after $\mathrm{I} / \mathrm{R}$ ) and $\mathrm{I} / \mathrm{R}+$ Wom (injected with wortmannin after I/R).

\section{Rat I/R model}

Male rats were anesthetized by abdominal injection of $40 \mathrm{mg} / 100 \mathrm{~g}$ urethane followed by midline laparotomy and systemic heparinization. Abdominal aorta was blocked $0.5 \mathrm{~cm}$ above the bifurcation of the common iliac artery with atraumatic artery clip such that the arterial pulse disappeared and lumen became flat below the clip to induce ischemia for $2 \mathrm{~h}$. The clamp was removed to allow reperfusion for another $2 \mathrm{~h}$. In the sham group, $1 \mathrm{ml}$ normal saline was injected into the sublingual vein instead of blocking the abdominal aorta. For lncRNA AK139328 knockdown, $100 \mu \mathrm{l}$ of $2.5 \mathrm{mg} / \mathrm{kg}$ AK139328 siRNAs were injected into the caudal vein of rats with hindlimb $\mathrm{I} / \mathrm{R}$ at 9:00 a.m. on the same day as I/R and $24 \mathrm{~h}$ later. The sequences of the 3 siRNAs used were:

sense 1, 5' -CAGCUAUCACAUGCCAGCAUC AUAU-3',

antisense 1, 5'-AUAUGAUGCUGGCAUGUGAU AGCUG -3';

sense 2, 5'- GCAUCUAAAGCUGGUGGCAAU

ACUA -3',

antisense 2, 5'- UAGUAUUGCCACCAGCUUUAG

AUGC -3';

sense $3,5^{\prime}$ - CCUUGGACUUCUGACUGAAUGA

ACU -3',

antisense 3, 5'- AGUUCAUUCAGUCAGAAGU

CCAAGG -3' (Invitrogen Inc., Carlsbad, CA, USA) [17].

For si-AK139328+Wom and I/R+Wom groups, $1 \mathrm{ml}$ wortmannin (1:400 dilution; Beijing ZhongshanJinqiao Biotechnology Co., Ltd., Beijing, China) was injected into the sublingual vein after I/R.

\section{In vitro vascular endothelial cell $\mathrm{I} / \mathrm{R}$ model}

Hindlimbs were harvested from 4 healthy adult male Wistar rats $(200 \sim 250 \mathrm{~g})$ and homogenized in D-Hank's medium after removing the veins and cutting them into

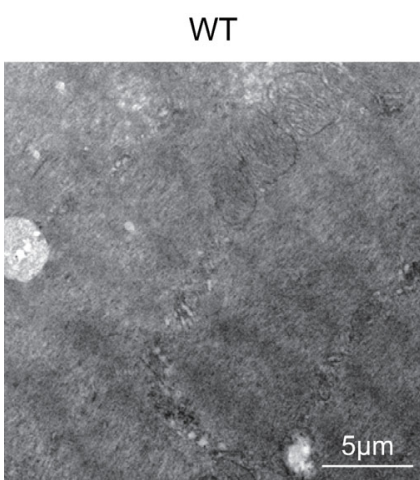

Sham + si-AK139328

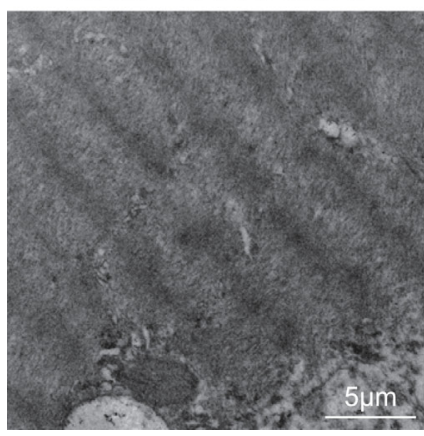

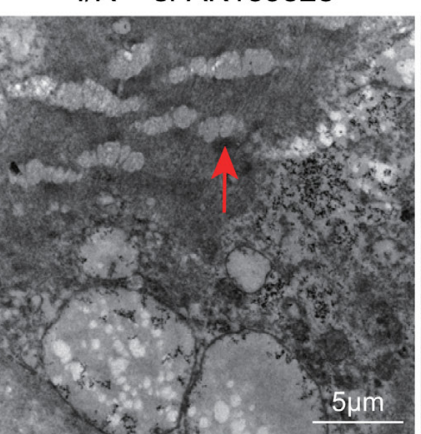

$\mathrm{I} / \mathrm{R}$
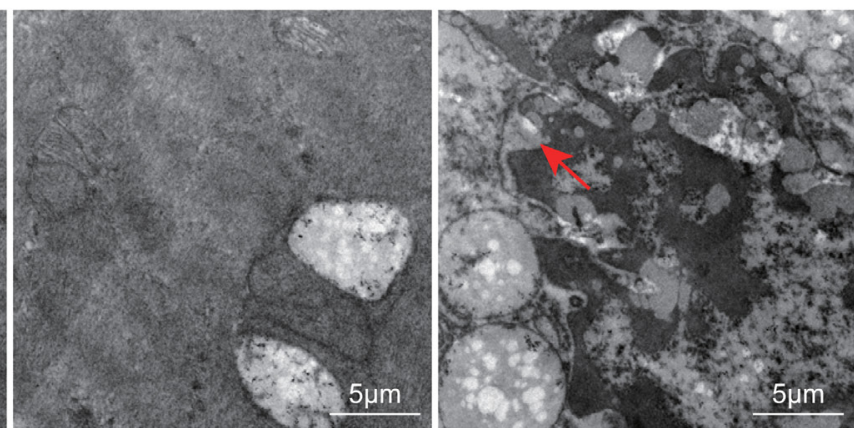

I/R + si-AK139328 + Wom

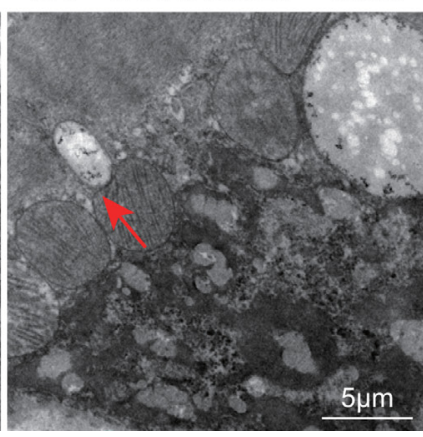

I/R + si-AK139328 + NC
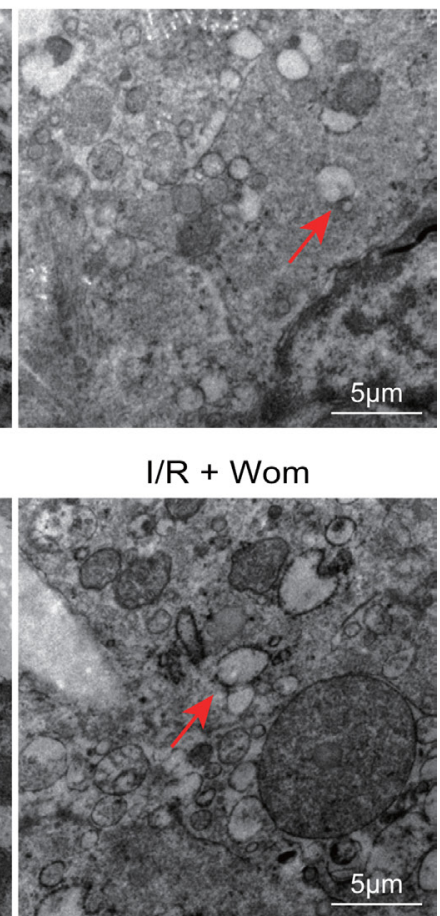

Figure 13: Ultrastructural analysis of arterial vascular endothelial cells in the rat hindlimb I/R model by transmission electron microscopy. Representative TEM images $(1000 \times)$ of the lateral extremity arterial sections from the rat groups $1-8$ in the hindlimb I/R model. The arrows indicate lipid vacuoles; 64 rats were included in the experiment (8 in each group). 
small pieces. The homogenate was sieved through $100-$ and $200-\mu \mathrm{m}$ mesh screens. Microvascular tissues on the screen were centrifuged in DMEM and digested with $5 \mathrm{ml}$ of $0.2 \%$ collagenase I for $20 \mathrm{~min}$. The homogenates were centrifuged $\left(12000 \mathrm{rpm} / \mathrm{min}\right.$, at $\left.4{ }^{\circ} \mathrm{C}\right)$ again and the cells from the pellet were cultured in $6 \mathrm{ml}$ of complete DMEM medium supplemented with endothelial cell growth factor (ECGF) and 30\% fetal bovine serum (FBS) for $48 \mathrm{~h}$. The cells were trypsinized when they reached $80 \%$ confluence.

For oxygen-glucose deprivation experiments to simulate $\mathrm{I} / \mathrm{R}$, endothelial cells were washed in PBS twice and incubated in a closed anoxic tank with sugar- free Krebs solution at $37^{\circ} \mathrm{C}$ with $95 \% \mathrm{~N}_{2}+5 \% \mathrm{CO}_{2}$ for $4 \mathrm{~h}$. Subsequently, the cells were cultured in serum-free DMEM medium for $12 \mathrm{~h}$. These cells were included in the model group. Cells in the control group were cultured in a normal incubator for $16 \mathrm{~h}$. Altogether, cells were divided into 6 groups: control, model, model + si AK139328 NC (transfected with si-AK139328 NC), model + siAK139328 (transfected with siAK139328), model + si-AK139328 + LY294002 [transfected with si-AK139328 and treated with $50 \mu \mathrm{M}$ LY294002 (specific inhibitor of PI3K/Akt signaling pathway, which can permeate cells, specifically inhibit PI3K and PI3K/Akt signaling pathway) (Cell

\section{A}
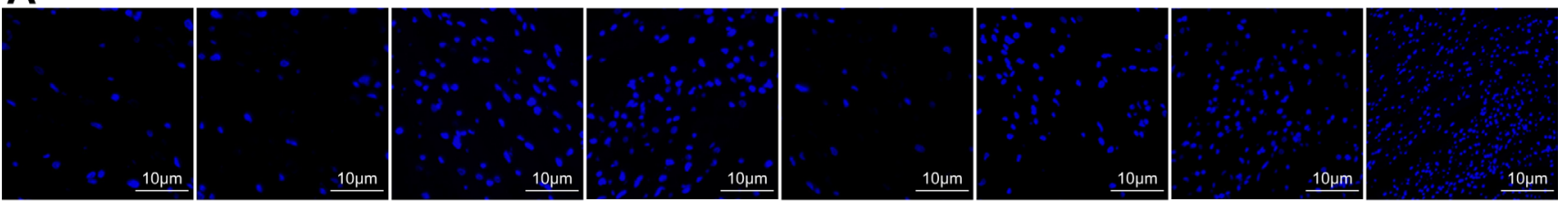

B
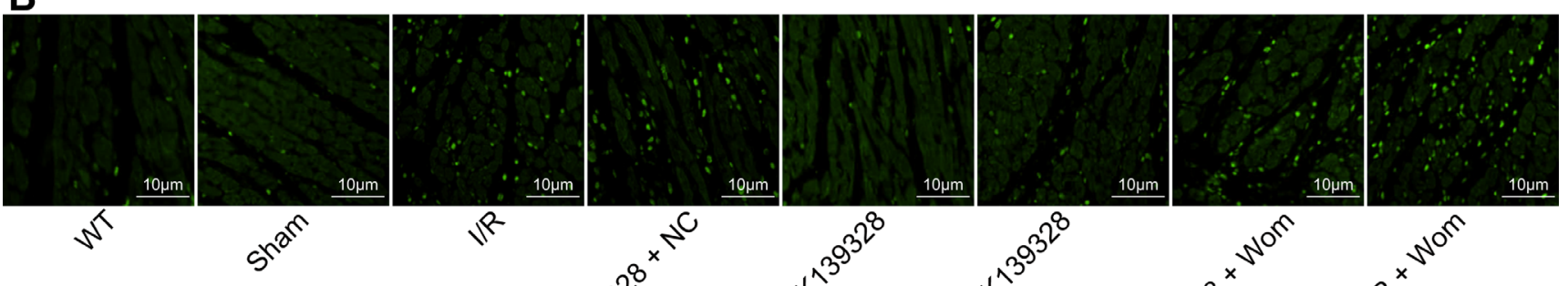

C
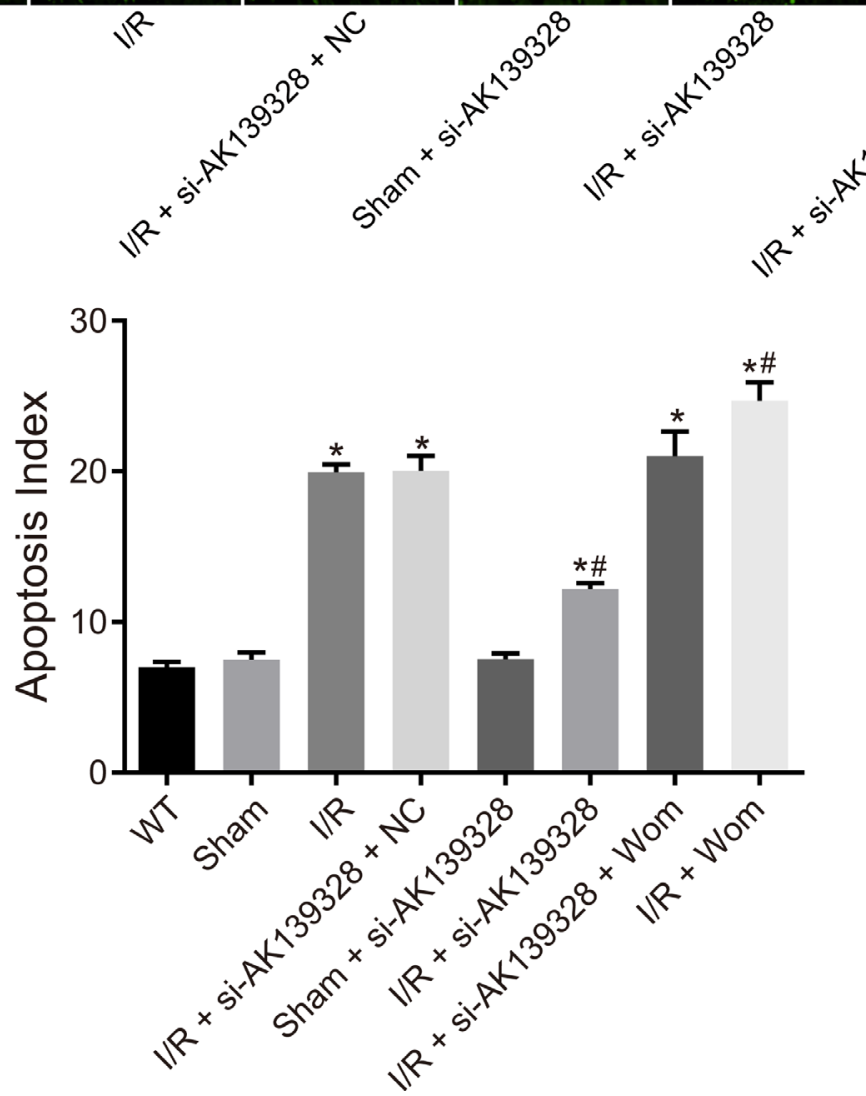

Figure 14: TUNEL analysis of apoptosis in gastrocnemius muscle cells in rats subjected to I/R. Representative images $(200 \times)$ showing $(\mathbf{A})$ DAPI and $(\mathbf{B})$ TUNEL stained gastrocnemius muscle sections from rat groups 1-8 in the hindlimb I/R model. (C) Quantitative analysis of TUNEL-positive (apoptotic) cells in gastrocnemius muscle sections from rat groups 1-8 in the hindlimb I/R model. Note: * denotes $P<0.05$ compared with sham group; ${ }^{*}$ denotes $P<0.05$ compared with $\mathrm{I} / \mathrm{R}$ group; 64 rats were included in the experiment ( 8 in each group) and differences between groups were analyzed by $t$-test. 
Signaling Technologies, Beverly, MA, USA)], and model + LY294002 (treated with $50 \mu \mathrm{M}$ LY294002) groups. All transfections and treatments were performed $12 \mathrm{~h}$ after oxygen-glucse deprivation. LY294002 is a specific inhibitor of PI3K/Akt signaling pathway which was obtained from Cell Signaling Technologies, Beverly, MA, USA.

\section{Reverse transcription quantitative polymerase chain reaction ( $R T-q P C R)$}

Total RNA was extracted from gastrocnemius muscle tissues with Trizol (Life Technologies, USA) according to manufacturer's instructions. All primer sequences (Table 6) were synthesized by TakaraHoldings Inc. (Tokyo, Japan) [17]. We performed reverse transcription of $1 \mu \mathrm{g}$ RNA from all samples with the reverse transcription kit (Takara Bio, CO., Ltd., Dalian, Liaoning, China). The cycling conditions were $37^{\circ} \mathrm{C}$ for 15 mins, $95^{\circ} \mathrm{C}$ for 5 secs and $4^{\circ} \mathrm{C}$ for 50 mins. The cDNA samples were stored at $-80^{\circ} \mathrm{C}$.

QPCR was performed with the kit (RR82LR, Takara Bio, CO., Ltd., Dalian, Liaoning, China) in a StepOne fluorescent quantitative PCR System (Applied Biosystems, Foster city, California, USA). The reaction mixture contained $2 \mu \mathrm{S} \mathrm{SYBR}{ }^{\circledR}$ Green I fluorescent dye, $0.8 \mu \mathrm{l}$ each of $10 \mu \mathrm{M}$ forward and reverse primers, $2 \mu \mathrm{l}$ cDNA and $6.4 \mu \mathrm{l}$ distilled water. The qPCR reaction was $95^{\circ} \mathrm{C}$ for $30 \mathrm{~s}, 95^{\circ} \mathrm{C}$ for $5 \mathrm{~s}$ and $60^{\circ} \mathrm{C}$ for $30 \mathrm{~s}$ and 40 cycles of $95^{\circ} \mathrm{C}$ for $15 \mathrm{~s}, 60^{\circ} \mathrm{C}$ for $1 \mathrm{~min}$ and $95^{\circ} \mathrm{C}$ for $15 \mathrm{~s}$. The relative expression of the target genes was calculated by $2^{-\Delta \Delta \mathrm{CT}}$ method with $\beta$-actin as an internal reference.

\section{Western blotting}

Gastrocnemius muscle tissues were quickly dissected from mice, frozen in liquid nitrogen and stored at $-80^{\circ} \mathrm{C}$. Protein lysates were prepared by incubating $100 \mu \mathrm{g}$ muscle tissue with $500 \mu \mathrm{l}$ lysis solution for $5 \mathrm{~min}$. The homogenate was centrifuged at $12000 \mathrm{rpm}$ for $10 \mathrm{~min}$ at $4{ }^{\circ} \mathrm{C}$ and the protein concentration was determined with bicinchoninic acid (BCA) method.

The protein lysates $(20 \mu \mathrm{g})$ were boiled at $100^{\circ} \mathrm{C}$ for 10 min in $5 \times$ loading buffer and separated on a $10 \%$ SDS PAGE and subsequently transferred to polyvinylidene fluoride (PVDF). The blots were blocked with 5\% skimmed milk for $1 \mathrm{~h}$ and incubated with primary rabbit anti-rat PI3K, p-PI3K, Akt and p-Akt (1:1000; Cell Signaling Technology, USA) antibodies at $4^{\circ} \mathrm{C}$ overnight. Then, after washing the membranes thrice with PBST for 10 minutes, they were incubated with HRP-conjugated goat anti-rabbit secondary antibody $(1: 4000)$ at $37^{\circ} \mathrm{C}$ for $1 \mathrm{~h}$. Then, the blots were developed with ECL (Amersham, Arlington Heights, IL, USA) and then developed. The protein bands were quantified by the Labwork 4.6 software in UVP image processing system using GAPDH as internal reference.

\section{Analysis of reactive oxygen species}

After reperfusion, the central coronal sections from rat gastrocnemius muscles were paraffinembedded and cut into $5 \mu \mathrm{m}$ slides. Then, the slices were incubated with $2 \mu \mathrm{M}$ dihydroethidium (DHE) in the dark for 15 minutes. The slides were observed under the fluorescent microscope. Rat VECs from all groups were incubated with $2 \mu \mathrm{M}$ dihydroethidium (DHE) in the dark for 30 minutes. Then, the fluorescent intensity was measured in a microplate reader at 488 $\mathrm{nm}$ excitation wavelength.

\section{Hemotoxylin and eosin $(\mathrm{H \& E})$ staining}

Rat skeletal muscle tissue samples from the left lower limb $\left(1.0 \mathrm{~cm}^{3}\right)$ and left external iliac artery $(0.5 \mathrm{~cm})$ were fixed in $10 \%$ neutral formalin, paraffin embedded and sliced. Tissue sections were stained with the H\&E kit (Beijing Solarbio Science \& Technology Co., Ltd, Beijing, China) according to manufacturer's instructions and imaged under a light microscope (IX53, Olympus Optical Co., Ltd, Tokyo, Japan).

\section{Transmission electron microscopy (TEM)}

Lower extremity artery of rats was harvested in sterile PBS. After removing endovascular blood and fat from the outer membrane of the aorta, blood vessels were opened longitudinally and placed in a $60 \mathrm{~mm}$ with DMEM containing $75 \mu \mathrm{g} / \mathrm{ml}$ endothelial cell growth supplement (ECGS). Then, $1 \mathrm{~mm}^{2}$ pieces were cut with a surgical knife, placed in a culture plate with the inner membranes facing down and incubated at $37^{\circ} \mathrm{C}$ and $5 \% \mathrm{CO}_{2}$ for $20 \mathrm{~min}$. Then, they were incubated in $1.2 \mathrm{~mL}$ DMEM medium with $75 \mu \mathrm{g} /$ $\mathrm{ml}$ ECGS for 3 days. The vessel pieces were then removed carefully so that the few cells growing around them were not disturbed and fresh medium was added every $2 \sim 3$ days. Endothelial cells were confirmed by immunofluorescence for von Willebrand factor (vWF) antigen. The endothelial cells were then fixed in $2.5 \%$ glutaraldehyde for $4 \mathrm{~h}$, followed by $1 \%$ crane acid for $2 \mathrm{~h}$ and $70 \%$ ethanol at $4{ }^{\circ} \mathrm{C}$ overnight. Then, the cells were embedded with Epon812 (ethoxyline resin), sliced with a LKB ultramicrotome and stained with uranium acetate and citric acid. Images were captured using the transmission electron microscope (IX53, Olympus Optical Co., Ltd, Tokyo, Japan).

\section{ELISA}

Blood (4 ml) from the abdominal aorta was centrifuged at $1000 \mathrm{~g}$ for $5 \mathrm{~min}$ and the supernatant (plasma) was preserved at $-80^{\circ} \mathrm{C}$. Plasma levels of TNF- $\alpha$ and VCAM-1 were measured according to manufacturer's instructions for the corresponding ELISA kits (Shanghai Westang Bio-tech Co., Ltd, Shanghai, China). 
Table 6: Primer sequences for reverse transcrption quantitative polymerase chain reaction (RT-qPCR)

\begin{tabular}{ll}
\hline Primer & Primer sequence (5'-3') \\
\hline \multirow{2}{*}{ LncRNA AK139328 } & F: 5'-CCAGTTCTTGGTCCTGGTGT-3' \\
& R: 5'-GTGTCTGCAACCCGATAGGT-3' \\
PI3K & F: 5'-CAATACTTGATGTGGCTGAC-3' \\
& R: 5'-TGACGCAATGTTTGACTT-3' \\
Akt & F: 5'-TTTATTGGCTACAAGGAACG-3' \\
& R: 5'-AGTCTGAATGGCGGTGGT-3' \\
eNOS & F: 5'-CCAGCTAGCCAAAGTCACCAT-3' \\
& R: 5'-GTCTCGGAGCCATACAGGATT-3' \\
\multirow{2}{*}{$\beta$-actin } & F: 5'-TCAGGTCATCACTATCGGCAAT-3' \\
& R: 5'-AAAGAAAGGGAGTAAAACGCA-3' \\
\hline
\end{tabular}

Note: F, forward; R, reverse.

\section{Immunohistochemical staining}

Blood vessels were fixed in $4 \%$ paraformaldehyde and dehydrated with serial concentrations of ethanol. After paraffin embedding, the vessels were sectioned. Then, the sections were deparaffinized, hydrated and incubated with $1 \%$ hydrogen peroxide $\left(\mathrm{H}_{2} \mathrm{O}_{2}\right)$ solution for $10 \mathrm{~min}$ at room temperature to eliminate endogenous peroxidase activity. Then, the samples were blocked with goat serum and incubated with anti-caspase-3 antibodies (Beijing ZhongShan GoldenBridge Biological Technology Co., Ltd., Beijing, China) at $4^{\circ} \mathrm{C}$ overnight. The samples were further incubated with anti-mouse digoxigenin followed by biotinylated anti-mouse $\operatorname{IgG}$ at $37^{\circ} \mathrm{C}$ for 30 min. Then, streptavidin was added and the slides were developed with diaminobenzidine (DAB). Sections were then counterstained with hematoxylin and images captured with a light microscope.

\section{Measurement of caspase-3 activity}

Caspase- 3 activity was measured with the assay kit (C1115, Beyotime Biotechnology Co., Shanghai, China) according to manufacturer's instructions. Tissues were homogenized on ice, centrifuged at $15,000 \mathrm{~g}$ for $10 \mathrm{mins}$ and the supernatants were used for analysis. The reaction included incubation of tissue supernatants with Ac-DEVDAMC (tetrapeptide fluorescent substrate of caspase-3) at $37^{\circ} \mathrm{C}$ for $1 \mathrm{~h}$. The samples were read in the fluorescence spectrophotometer (POLARstar, Ortenberg, Germany) at $380 \mathrm{~nm}$ excitation and $405 \mathrm{~nm}$ emission. Quantification was performed using the standard curve. The experiment was repeated thrice.

\section{Estimation of serum malondialdehyde (MDA) and creatine kinase (CK) activity}

Serum MDA levels and creatine kinase activities were measured by the Lipid Peroxidation MDA Assay Kit (Beyotime Biotechnology Co., Shanghai, China) and
Creatine Kinase Activity Assay Kit (Sigma, St Louis MO, USA), respectively, according to manufacturer's instructions.

\section{Measurement of circulating endothelial cells (CECs)}

Venous blood $(1.6 \mathrm{ml})$ was mixed with $0.4 \mathrm{ml}$ anticoagulant (3.8\% sodium citrate) and centrifuged for $20 \mathrm{~min}$ at $2350 \mathrm{rpm}$. Then, $0.2 \mathrm{ml}$ of $0.1 \%$ adenosine 5 '-diphosphate (ADP) was added to the supernatant and centrifuged similarly. Further, $0.1 \mathrm{ml}$ of re-centrifuged supernatant was mixed with a small amount of PBS for $10 \mathrm{~min}$ and added onto a cover glass slide. The average numbers of CECs were determined by counting the numbers of CECs in $0.9 \mu \mathrm{l}$ under an ultramicroscope. Experiments were repeated thrice.

\section{In situ detection of cell apoptosis in gastrocnemius muscle}

Lower part of rat gastrocnemius muscle was fixed in $4 \%$ paraformaldehyde for $4 \sim 8 \mathrm{~h}$, paraffin embedded and cut into $50 \mu \mathrm{m}$ slices. Cellular apoptosis was determined by terminal deoxynucleotidytransferase mediated d-UTP nick end labeling (TUNEL) assay kit (Wuhan Boster Biological Technology Ltd., Wuhan, China). The slices were photographed with Nikon E600 and the apoptosis index (AI; ratio of apoptotic to total nuclei) was analyzed by the LabWorks 4.0 software.

\section{Statistical analysis}

All data were analyzed by SPSS 22.0 software (IBM Corp., Armonk, NY, USA) and presented as mean \pm standard deviation. Differences between groups were analyzed by $t$-test. $P<0.05$ was considered as statistically significant.

\section{ACKNOWLEDGMENTS}

We acknowledge the reviewers for their helpful comments on this paper. 


\section{CONFLICTS OF INTEREST}

All authors declare that there are no conflicts of interest.

\section{FUNDING}

This study was supported by the National Natural Science Foundation of China (NSFC, No. 31201960).

\section{REFERENCES}

1. Oklu R, Albadawi H, Jones JE, Yoo HJ, Watkins MT. Reduced hind limb ischemia-reperfusion injury in Tolllike receptor-4 mutant mice is associated with decreased neutrophil extracellular traps. J Vasc Surg. 2013; 58:162736. https://doi.org/10.1016/j.jvs.2013.02.241. [PubMed]

2. Halladin NL, Ekeløf S, Alamili M, Bendtzen K, Lykkesfeldt J, Rosenberg J, Gögenur I. Lower limb ischaemia and reperfusion injury in healthy volunteers measured by oxidative and inflammatory biomarkers. Perfusion. 2015; 30:64-70. https://doi.org/10.1177/0267659114530769. [PubMed]

3. Kalogeris T, Baines CP, Krenz M, Korthuis RJ. Cell biology of ischemia/reperfusion injury. Int Rev Cell Mol Biol. 2012; 298:229-317. https://doi.org/10.1016/B978-0-12-3943095.00006-7. [ [PubMed]

4. Takhtfooladi MA, Moayer F, Takhtfooladi HA. Beneficial effect of pentoxifylline into the testis of rats in an experimental model of unilateral hindlimb ischemia/ reperfusion injury. Int Braz J Urol. 2015; 41:576-83. https:// doi.org/10.1590/S1677-5538.IBJU.2014.0263. [PubMed]

5. Masoumy M, Yu J, Liu JY, Yanasak N, Middleton C, Lamoke F, Mozaffari MS, Baban B. The role of indoleamine 2,3 dioxygenase in beneficial effects of stem cells in hind limb ischemia reperfusion injury. PLoS One. 2014; 9:e95720. https://doi.org/10.1371/journal.pone.0095720. [PubMed]

6. Takhtfooladi H, Takhtfooladi M, Moayer F, Mobarakeh S. Melatonin attenuates lung injury in a hind limb ischemiareperfusion rat model. Rev Port Pneumol. 2015; 21:30-35. https://doi.org/10.1016/j.rppnen.2014.01.010. [PubMed]

7. Hsu KY, Chen CH, Shih PC, Huang CJ. Adverse effects of bilateral lower limb ischemia-reperfusion on inducing kidney injuries in rats could be ameliorated by platonin. Acta Anaesthesiol Taiwan. 2012; 50:63-68. https://doi. org/10.1016/j.aat.2012.05.010. [PubMed]

8. Wang XY, Chen XL, Wang L, Chen HW. Highdose glucocorticoids increases the expression of mineralocorticoid receptor in vascular endothelial cells. Eur Rev Med Pharmacol Sci. 2015; 19:4314-23. [PubMed]

9. Shoda T, Futamura K, Orihara K, Emi-Sugie M, Saito $\mathrm{H}$, Matsumoto K, Matsuda A. Recent advances in understanding the roles of vascular endothelial cells in allergic inflammation. Allergol Int. 2016; 65:21-29. https:// doi.org/10.1016/j.alit.2015.08.001. [PubMed]

10. Dong W, Xiao S, Cheng M, Ye X, Zheng G. Minocycline induces protective autophagy in vascular endothelial cells exposed to an in vitro model of ischemia/reperfusioninduced injury. Biomed Rep. 2016; 4:173-77. https://doi. org/10.3892/br.2015.554. [PubMed]

11. Michalik KM, You X, Manavski Y, Doddaballapur A, Zörnig M, Braun T, John D, Ponomareva Y, Chen W, Uchida S, Boon RA, Dimmeler S. Long noncoding RNA MALAT1 regulates endothelial cell function and vessel growth. Circ Res. 2014; 114:1389-97. https://doi. org/10.1161/CIRCRESAHA.114.303265. [PubMed]

12. Schonrock N, Harvey RP, Mattick JS. Long noncoding RNAs in cardiac development and pathophysiology. Circ Res. 2012; 111:1349-62. https://doi.org/10.1161/ CIRCRESAHA.112.268953. [PubMed]

13. Johnson R. Long non-coding RNAs in Huntington's disease neurodegeneration. Neurobiol Dis. 2012; 46:245-54. https://doi.org/10.1016/j.nbd.2011.12.006. [PubMed]

14. Pauli A, Valen E, Lin MF, Garber M, Vastenhouw NL, Levin JZ, Fan L, Sandelin A, Rinn JL, Regev A, Schier AF. Systematic identification of long noncoding RNAs expressed during zebrafish embryogenesis. Genome Res. 2012; 22:577-91. https://doi.org/10.1101/gr.133009.111. [PubMed]

15. Dal Ponte C, Alchera E, Follenzi A, Imarisio C, Prat M, Albano E, Carini R. Pharmacological postconditioning protects against hepatic ischemia/reperfusion injury. Liver Transpl. 2011; 17:474-82. https://doi.org/10.1002/1t.22256. [PubMed]

16. Huang JB, Ding Y, Huang DS, Liang AJ, Zeng WK, Zeng ZP, Qin CQ, Barden B. Inhibition of the PI3K/AKT pathway reduces tumor necrosis factor-alpha production in the cellular response to wear particles in vitro. Artif Organs. 2013; 37:298-307. https://doi.org/10.1111/j.15251594.2012.01568.x. [PubMed]

17. Chen Z, Jia S, Li D, Cai J, Tu J, Geng B, Guan Y, Cui Q, Yang J. Silencing of long noncoding RNA AK139328 attenuates ischemia/reperfusion injury in mouse livers. PLoS One. 2013; 8:e80817. https://doi.org/10.1371/journal. pone.0080817. [PubMed]

18. Chen Z, Luo Y, Yang W, Ding L, Wang J, Tu J, Geng B, Cui Q, Yang J. Comparison Analysis of Dysregulated LncRNA Profile in Mouse Plasma and Liver after Hepatic Ischemia/ Reperfusion Injury. PLoS One. 2015; 10:e0133462. https:// doi.org/10.1371/journal.pone.0133462. [PubMed]

19. Guttman M, Rinn JL. Modular regulatory principles of large non-coding RNAs. Nature. 2012; 482:339-46. https://doi. org/10.1038/nature10887. [PubMed]

20. Chen Z, Yu C, Zhan L, Pan Y, Chen L, Sun C. LncRNA CRNDE promotes hepatic carcinoma cell proliferation, migration and invasion by suppressing miR-384. Am J Cancer Res. 2016; 6:2299-309. [PubMed] 
21. Song P, Yin SC. Long non-coding RNA EWSAT1 promotes human nasopharyngeal carcinoma cell growth in vitro by targeting miR-326/-330-5p. Aging (Albany NY). 2016; 8:2948-60. https://doi.org/10.18632/aging.101103. [PubMed]

22. Wan G, Zhou W, Hu Y, Ma R, Jin S, Liu G, Jiang Q. Transcriptional Regulation of lncRNA Genes by Histone Modification in Alzheimer's Disease. Biomed Res Int. 2016; 2016:3164238. https://doi.org/10.1155/2016/3164238. [PubMed]

23. Masuda Y, Yazawa J, Makino Y, Takada K. Pi3-kinase inhibitor ly294002 repressed the expression of thrombinactivatable fibrinolysis inhibitor in human hepatoma hepg2 cells. Biol Pharm Bull. 2015; 38:1529-35. https://doi. org/10.1248/bpb.b15-00295. [PubMed]

24. Ke B, Shen XD, Ji H, Kamo N, Gao F, Freitas MC, Busuttil RW, Kupiec-Weglinski JW. HO-1-STAT3 axis in mouse liver ischemia/reperfusion injury: regulation of TLR4 innate responses through PI3K/PTEN signaling. J Hepatol. 2012; 56:359-66. https://doi.org/10.1016/j.jhep.2011.05.023. [PubMed]

25. Dong Y, Liang G, Yuan B, Yang C, Gao R, Zhou X. MALAT1 promotes the proliferation and metastasis of osteosarcoma cells by activating the PI3K/Akt pathway. Tumour Biol. 2015; 36:1477-86. https://doi.org/10.1007/ s13277-014-2631-4. [PubMed]

26. Yang C, Li X, Wang Y, Zhao L, Chen W. Long non-coding RNA UCA1 regulated cell cycle distribution via CREB through PI3-K dependent pathway in bladder carcinoma cells. Gene. 2012; 496:8-16. https://doi.org/10.1016/j. gene.2012.01.012. [PubMed]

27. Okoh VO, Felty Q, Parkash J, Poppiti R, Roy D. Reactive oxygen species via redox signaling to PI3K/AKT pathway contribute to the malignant growth of 4-hydroxy estradioltransformed mammary epithelial cells. PLoS One. 2013; 8:e54206. https://doi.org/10.1371/journal.pone.0054206. [PubMed]

28. Xiao M, Men LN, Xu MG, Wang GB, Lv HT, Liu C. Berberine protects endothelial progenitor cell from damage of TNF- $\alpha$ via the PI3K/AKT/eNOS signaling pathway. Eur J Pharmacol. 2014; 743:11-16. https://doi.org/10.1016/j. ejphar.2014.09.024. [PubMed]

29. Yang JB, Quan JH, Kim YE, Rhee YE, Kang BH, Choi IW, Cha GH, Yuk JM, Lee YH. Involvement of PI3K/AKT and MAPK Pathways for TNF- $\alpha$ Production in SiHa Cervical Mucosal Epithelial Cells Infected with Trichomonas vaginalis. Korean J Parasitol. 2015; 53:371-77. https://doi. org/10.3347/kjp.2015.53.4.371. [PubMed]

30. Chen HW, Lin AH, Chu HC, Li CC, Tsai CW, Chao CY, Wang CJ, Lii CK, Liu KL. Inhibition of TNF- $\alpha$-Induced Inflammation by andrographolide via down-regulation of the PI3K/Akt signaling pathway. J Nat Prod. 2011; 74:2408-13. https://doi.org/10.1021/np200631v. [PubMed]
31. Tsoyi K, Jang HJ, Nizamutdinova IT, Park K, Kim YM, Kim HJ, Seo HG, Lee JH, Chang KC. PTEN differentially regulates expressions of ICAM-1 and VCAM-1 through PI3K/Akt/GSK-3ß/GATA-6 signaling pathways in TNF- $\alpha$-activated human endothelial cells. Atherosclerosis. 2010; 213:115-21. https://doi.org/10.1016/j. atherosclerosis.2010.07.061. [PubMed]

32. Jiang S, Zhu W, Li C, Zhang X, Lu T, Ding Z, Cao K, Liu L. $\alpha$-Lipoic acid attenuates LPS-induced cardiac dysfunction through a PI3K/Akt-dependent mechanism. Int Immunopharmacol. 2013; 16:100-07. https://doi. org/10.1016/i.intimp.2013.03.024. [PubMed]

33. Zhou H, Qian J, Li C, Li J, Zhang X, Ding Z, Gao X, Han Z, Cheng Y, Liu L. Attenuation of cardiac dysfunction by HSPA12B in endotoxin-induced sepsis in mice through a PI3K-dependent mechanism. Cardiovasc Res. 2011; 89:109-18. https://doi.org/10.1093/cvr/cvq268. [PubMed]

34. Widgerow AD. Ischemia-reperfusion injury: influencing the microcirculatory and cellular environment. Ann Plast Surg. 2014; 72:253-60. https://doi.org/10.1097/ SAP.0b013e31825c089c. [PubMed]

35. Kazanci A, Seckin H, Karadeniz U, Kazanci D, Turan S, Kazanci B, Yigitkanli K, Bavbek M. Comparison of the effect of mexiletine and methylprednisolone on neural function and histopathological damage after transient spinal cord ischemia in rabbits. Turk Neurosurg. 2010; 20:43-49. [PubMed]

36. Moussa MD, Santonocito C, Fagnoul D, Donadello K, Pradier O, Gaussem P, De Backer D, Vincent JL. Evaluation of endothelial damage in sepsis-related ARDS using circulating endothelial cells. Intensive Care Med. 2015; 41:231-38. https://doi.org/10.1007/s00134-014-3589-9. [PubMed]

37. Ronzoni M, Manzoni M, Mariucci S, Loupakis $F$, Brugnatelli S, Bencardino K, Rovati B, Tinelli C, Falcone A, Villa E, Danova M. Circulating endothelial cells and endothelial progenitors as predictive markers of clinical response to bevacizumab-based first-line treatment in advanced colorectal cancer patients. Ann Oncol. 2010; 21:2382-89. https://doi.org/10.1093/annonc/mdq261. [PubMed]

38. Aksu V, Yüksel V, Chousein S, Taştekin E, İşcan Ş, Sağiroğlu G, Canbaz S, Sunar H. The effects of sildenafil and n-acetylcysteine on ischemia and reperfusion injury in gastrocnemius muscle and femoral artery endothelium. Vascular. 2015; 23:21-30. https://doi. org/10.1177/1708538114527939. [PubMed]

39. Johnson M, Zaretskaya I, Raytselis Y, Merezhuk Y, McGinnis S, Madden TL. NCBI BLAST: a better web interface. Nucleic Acids Res. 2008; 36:W5-9. https://doi. org/10.1093/nar/gkn201. [PubMed] 